\title{
A Comparison of Uncertainty Analysis Methods Using a Groundwater Flow Model
}
P. G. Doctor
E. A. Jacobson
J. A. Buchanan

June 1988

Prepared for the U.S. Department of Energy under Contract DE-AC06-76RLO 1830

Pacific Northwest Laboratory Operated for the U.S. Department of Energy by Battelle Memorial Institute 


\title{
DISCLAIMER
}

This report was prepared as an account of work sponsored by an agency of the United States Government. Neither the United States Government nor any agency thereof, nor Battelle Memorial !nstitute, nor any or their employees, makes any warranty, expressed or implied, or assumes any legal liability or responsibility for the accuracy, completeness, or usefulness of any information, apparatus, product, or process disclosed, or represents that its use would not infringe privately owned rights. Reference herein to any specific commercial product, process, or service by trade name, trademark, manufacturer, or otherwise does not necessarily constitute or imply its endorsement, recommendation, or favoring by the United States Government of any agency thereof, or Battelie Memorial Institute. The views and opinions of authors expressed herein do not necessarily state or reflect those of the United States Government or any agency thereof, or Battelle Memorial Institute.

\author{
PACIFIC NORTHWEST LABORATORY \\ operated by \\ BATTELLE MEMORIAL INSTITUTE \\ for the \\ UNITED STATES DEPARTMENT OF ENERGY \\ under Contract DE-AC06-76RLO 1830
}

\begin{tabular}{|c|c|}
\hline \multicolumn{2}{|c|}{ Printed in the United 5 tates of America } \\
\hline \multicolumn{2}{|c|}{$\begin{array}{c}\text { Available from } \\
\text { National Technical Information Service }\end{array}$} \\
\hline \multicolumn{2}{|c|}{ United States Department of Commerce } \\
\hline \multicolumn{2}{|c|}{5285 Port Royal Road } \\
\hline \multicolumn{2}{|c|}{ Springfield, Virginia 22161} \\
\hline \multicolumn{2}{|c|}{$\begin{array}{l}\text { NTIS Price Codes } \\
\text { Microfiche A01 }\end{array}$} \\
\hline \multicolumn{2}{|c|}{ Printed Copy } \\
\hline Pages & $\begin{array}{l}\text { Price } \\
\text { Codes }\end{array}$ \\
\hline $001-025$ & $\mathrm{~A} 02$ \\
\hline $026-050$ & $\mathrm{~A} 03$ \\
\hline 051.075 & AO4 \\
\hline $076-100$ & A05 \\
\hline $101-125$ & A06 \\
\hline $126-150$ & $\mathrm{A07}$ \\
\hline $15 \uparrow-175$ & $A 0 B$ \\
\hline $176-200$ & $A 09$ \\
\hline $201-225$ & A010 \\
\hline $226-250$ & A011 \\
\hline $251-275$ & A012 \\
\hline $276-300$ & $\mathrm{~A} 013$ \\
\hline
\end{tabular}


PNL -5649

UC-70

A COMPARISON OF UNCERTAINTY ANALYSIS
METHODS USING A GROUNDWATER FLOW MODEL

P. G. Doctor

E. A. Jacobson

J. A. Buchanan

June 1988

Prepared for

the U.S. Department of Energy

under Contract DE-ACO6-76RLO 1830

Pacific Northwest Laboratory

Richland, Washington 99352 



\section{EXECUTIVE SUMMARY}

The evaluation of uncertainty in performance assessment modeling has been given a high priority by the U.S. Department of Energy's Office of Civilian Radioactive Waste Management (OCRWM). This report evaluates three uncertainty anaiysis methods that are proposed for use in performance assessment activities within the OCRWM and Nuclear Regulatory Commission (NRC) communities. The three methods are

- Monte Carlo simulation with unconstrained sampling

- Monte Carlo simulation with Latin Hypercube sampling

- first-order analysis.

Monte Carlo simulation with unconstrained sampling is a generally accepted uncertainty analysis method, but it has the disadvantage of being costly and time consuming. Latin Hypercube sampling was proposed to make Monte Carlo simulation more efficient. However, although it was originally formulated for independent variables, which is a major drawback in performance assessment modeling, Latin Hypercube can be used to generate correlated samples. The first-order method is efficient to implement because it is based on the firstorder Taylor series expansion; however, there is concern that it does not adequately describe the variability for compiex models.

These three uncertainty analysis methods were evaluated using a calibrated groundwater flow model of an unconfined aquifer in southern Arizona. The two simulation methods produced similar results, although the Latin Hypercube method tends to produce samples whose estimates of statistical parameters are closer to the desired parameters. The mean travel times for the first-order method does not agree with those of the simulations. In addition, the firstorder method produces estimates of variance in travel times that are more variable than those produced by the simulation methods, resulting in nonconservative tolerance intervals. 


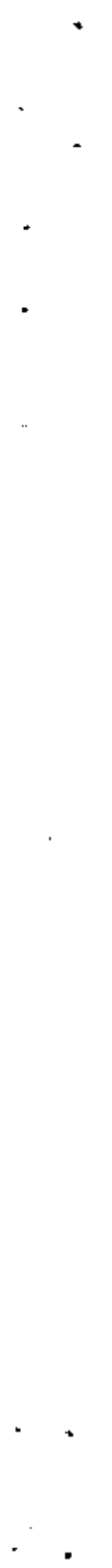




\section{ACKNOWLEDGMENTS}

The authors wish to acknowledge A. R. 01 sen and A. M. Liebetrau for their review comments on this report, the word processing support provided by the Sigma $V$ team, and the editing services of $K$. R. Hanson and $P$. C. Hays. 



\section{CONTENTS}

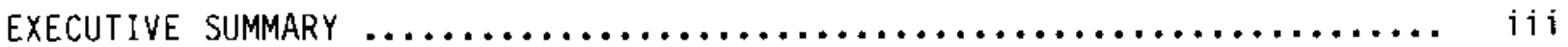

ACKNOWLEDGMENTS $\ldots \ldots \ldots \ldots \ldots \ldots \ldots \ldots \ldots \ldots \ldots \ldots \ldots \ldots \ldots \ldots \ldots \ldots \ldots$

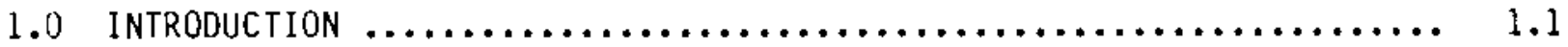

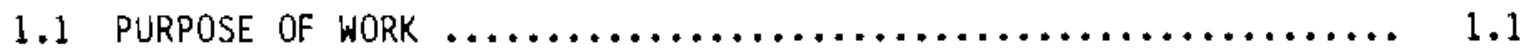

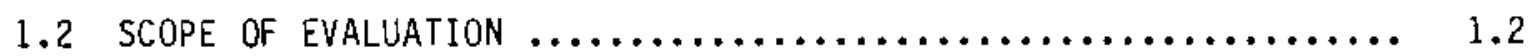

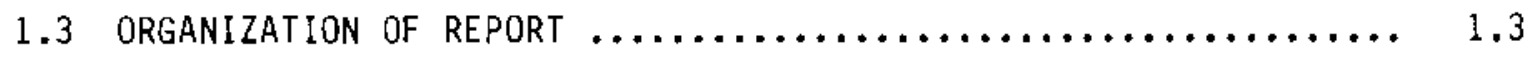

2.0 DESCRIPTION OF GROUNDWATER FLOW AND TRANSPORT MODELS

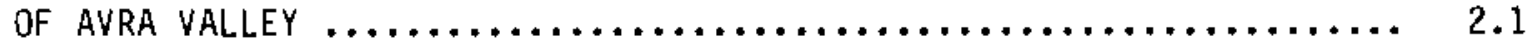

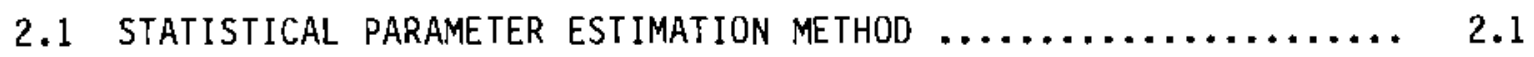

2.2 PATHLine AnD CUMUlative UUTFlow CALCULATIONS $\ldots \ldots \ldots \ldots \ldots \ldots$

3.0 DESCRIPTION OF UNCERTAINTY ANALYSIS METHODS $\ldots \ldots \ldots \ldots \ldots \ldots \ldots \ldots \ldots . . \ldots$

3.1 MONTE CARLO SIMULATION WITH UNCONSTRAINED SAMPLING $\ldots \ldots \ldots \ldots . .$.

3.2 MONTE CARLO SIMULATION WITH LATIN hyPERCUBE SAMPLING $\ldots \ldots \ldots \ldots .3 .3$

3.3 FIRST-ORDER METHOD $\ldots \ldots \ldots \ldots \ldots \ldots \ldots \ldots \ldots \ldots \ldots \ldots \ldots \ldots \ldots \ldots \ldots \ldots \ldots \ldots \ldots$

4.0 COMPARISON OF RESULTS FROM UNCERTAINTY ANALYSIS METHODS $\ldots \ldots \ldots \ldots . .4 .1$

4.1 COMPARISON OF THE INPUT VARIABLE DISTRIBUTIONS FOR

MONTE CARLO METHODS $\ldots \ldots \ldots \ldots \ldots \ldots \ldots \ldots \ldots \ldots \ldots \ldots \ldots \ldots . \ldots \ldots \ldots$

4.2 COMPARISON OF DISTRIBUTION FROM MODEL OUTPUT $\ldots \ldots \ldots \ldots \ldots \ldots \ldots$

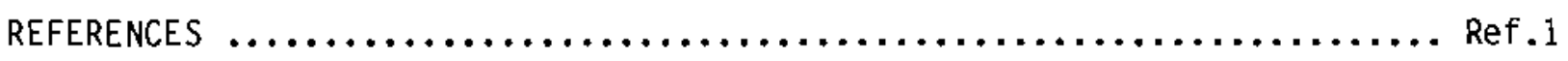




\section{FIGURES}

2.1 Location and Setting of Avra Valley, Arizona, and

Study Area Boundary ................................ 2.2

2.2 Contour Map of the Transmissivity Estimates from Log

Transmissivities Obtained by Parameter Estimation Model ......... 2.7

2.3 Contour Map of the Log-Transmissivity Estimation Errors ........ 2.8

2.4 Comparison of the 1940 Steady-State Hydraulic Heads and

the Heads Computed from Inverse Transmissivities .............. 2.9

2.5 Velocity Field Grid Imposed on Avra Valley Flow Model Grid ....... 2.11

3.1 Example of Probability Density Function Divided into

Equiprobable Intervals ............................. 3.4

4.1 Cumulative Frequency Histograms of Differences Between

Simulation Sample Transmissivity Means and Input Parameter

4.2 Cumulative Frequency Histograms of Differences Between

Simulation Sample Transmissivity Standard Deviations and

Input Parameter Values

4.3 Cumulative Frequency Histograms of Differences Between

Simulation Sample Transmissivity Pearson Product Moment.

Correlation Coefficients and Input Parameter values ........... 4.7

4.4 Examples of Realization of Cumulative Outflow Curves $\ldots \ldots \ldots \ldots . .4$

4.5 Cumulative Frequency Histograms of First Arrival Time .......... 4.10

4.6 Mean Cumulative Outflow Curves $\ldots \ldots \ldots \ldots \ldots \ldots \ldots \ldots \ldots \ldots \ldots \ldots \ldots . \ldots \ldots$

4.7 Lower Limit of Approximate 95\% Tolerance Interval for

A.1 Cumulative Frequency Histograms of Travel Times Corresponding

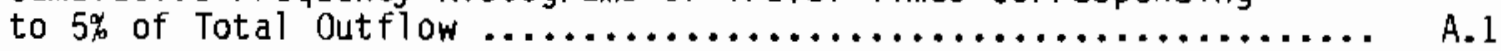

A.2 Cumulative Frequency Histograms of Travel Times Corresponding to $10 \%$ of Total Outflow .................................. A.2

A.3 Cumulative Frequency Histoyrams of Travel Times Corresponding

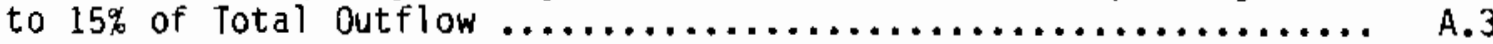


A.4 Cumulative Frequency Histograms of Travel Times Corresponding to $20 \%$ of Total outfiow ................................ A

A.5 Cumulative Frequency Histograms of Travel Times Corresponding

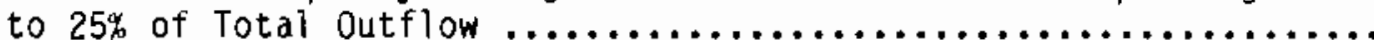

A.6 Cumulative Frequency Histograms of Travel Times Corresponding

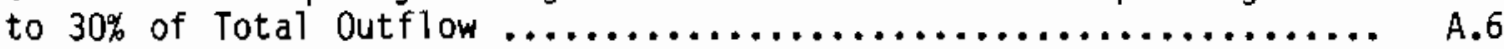

A.7 Cumulative Frequency Histograms of Travel Times Corresponding

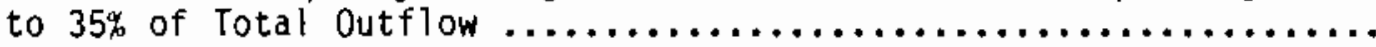

A.8 Cumulative Frequency Histograms of Travel Times Corresponding to $40 \%$ of Total Outflow.

A.9 Cumulative Frequency Histograms of Travel Times Corresponding to $45 \%$ of Total Outflow

A.10 Cumulative Frequency Histograms of Travel Times Corresponding to $50 \%$ of Total Outflow

A.11 Cumulative Frequency Histograms of Travel Times Corresponding

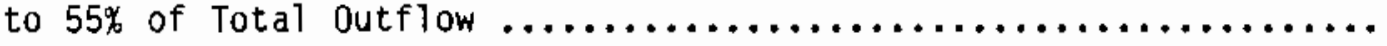

A.12 Cumulative Frequency Histograms of Travel Times Corresponding to $60 \%$ of Total Outflow

A.13 Cumulative Frequency Histograms of Travel Times Corresponding

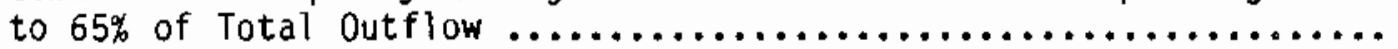

A.14 Cumulative Frequency Histograms of Travel Times Corresponding

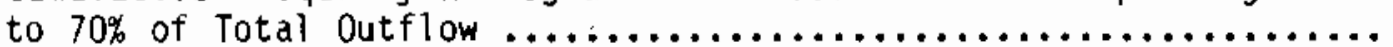

A.15 Cumulative Frequency Histograms of Travel Times Corresponding

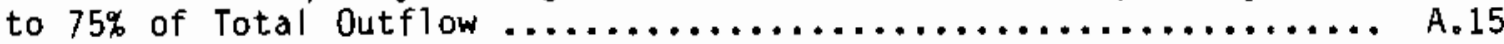

A.16 Cumulative Frequency Histograms of Travel Times Corresponding to $80 \%$ of Total Outflow.

A.17 Cumulative Frequency Histograms of Travel Times Corresponding

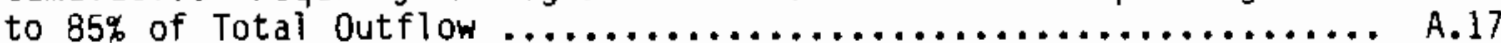

A.18 Cumulative Frequency Histograms of Travel Times Corresponding to $90 \%$ of Total Outflow

A.19 Cumulative Frequency Histograms of Travel Times Corresponding

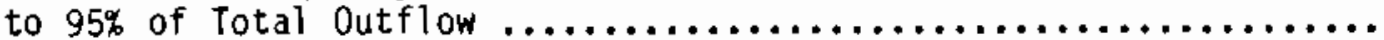

A.20 Cumulative Frequency Histograms of Travel Times Corresponding to $100 \%$ of Total Outflow 


\subsection{INTRODUCTION}

\subsection{PURPOSE OF WORK}

Evaluating uncertainties in the results from numerical modeling is an integral part of the performance assessment activities associated with potential geologic high-level radioactive waste repositories. The purpose of

this work is to compare several methods of evaluating these uncertainties in performance assessment modeling. A hydrologic model was chosen as the basis of comparison for two reasons:

1. The use of uncertainty analysis methods in hydrology is generally more developed than in other areas of performance assessment modeling.

2. Dependencies among the input variables in the model are well defined. Uncertainty analysis methods can be divided into two types: analytical and empirical. In the analytical methods, a probability distribution for the input variables is assumed and the uncertainty is propagated through the mode 1 to obtain estimates of the means and variances of the probability distributions of the outputs of the model (the performance assessment measures). The empirical methods consist of computer simulation experiments where different values for the input variables are assumed and the empirical probability distribution of the output is generated.

The advantage of the anajytical methods is that they are efficient from a computational standpoint. However, if the models are complex and nonlinear, the analytically derived mean and variance of the output may not be meaningful, particularly if the distributional properties of the output are substantially different from the input. The advantage of the empirical methods is that they provide accurate estimates of the probability distribution of the output of the models. However, for large or complex models, the amount of computing resources required to do the simulations may be prohibitive.

An uncertainty anajysis is conducted to determine the amount of variability in a model output that is caused by uncertainty or lack of knowledge in 
the model input. This report evaluates three uncertainty analysis methods used for quantifying the variability in a well-defined model.

The uncertainty analysis methods that are evaluated in this report are:

- Monte Carlo simulation with unconstrained sampling

- Monte Carlo simulation with Latin Hypercube sampling

- first-order analysis.

The first two methods are empirical and the third is an analytical method. Monte Carlo simulation with unconstrained sampling is a generally accepted uncertainty analysis method, but it has the disadvantage of being costly and time consuming. Latin Hypercube sampling was proposed to make Monte Carlo simulation more efficient; however, aithough it was originally formulated for independent variables, which is a major drawback for its use in performance assessment modeling, Latin Hypercube can be used to generate correlated samples. The first-order method is efficient to implement because it is based on the first-order Taylor series expansion, but there is concern that it does not adequately describe the variability for complex models.

These particular uncertainty analys is methods were chosen because within the DOE's Office of Civilian Radioactive Waste Management (OCRWM) and the Nuclear Regulatory Commission communities they have been proposed as the uncertainty analysis methods for performance assessment modeling. Pacific Northwest Laboratory ( $\mathrm{PNL}$ ) was requested to compare these methods as part of $\mathrm{DOE}^{\prime} \mathrm{S}$ Performance Assessment Scientific Support Program.

\subsection{SCOPE OF EVALUATION}

A hydrologic modeling problem was selected for the comparative study reported here. The hydrologic system being modeled is the unconfined aquifer of the Avra Valley in Arizona. The Avra Valley was chosen because it is a well-studied aquifer system. There is a large quantity of transmissivity and hydraulic head data, and a calibrated groundwater flow model is available. Uncertainty in transmissivity data are assumed, and the objective of the uncertainty analysis is to determine the effect of this uncertainty on the travel times from a line source within the aquifer to an outflow boundary. 


\subsection{ORGANIZATION OF REPORT}

The remainder of the report is divided into three sections. Section 2.0 describes the Avra Valley aquifer and the development of the calibrated flow model. The three uncertainty analysis methods evaluated in this report are described in the Section 3.0. Section 4.0 compares the results of the three uncertainty analysis methods on the travel times of contaminants in the Avra valley. 



\subsection{DESCRIPTION OF GROUNDWATER FLOW AND TRANSPORT \\ MODELS OF AVRA VALLEY}

Data from the Avra Valley aquifer in southern Arizona were used for the comparison of uncertainty methods. This aquifer was chosen because a calibrated groundwater flow model and corresponding parameter uncertainties were obtained by applying a statistical parameter estimation method to the field data (C1ifton and Neuman 1982).

Avra Valley, located in southern Arizona, is a deep elongated basin, which contains an extensive alluvial aquifer (Figure 2.1). A detailed geologic description of the valley and aquifer can be found in the thesis by Clifton (1981), and assumptions about the groundwater flow model are described in Clifton and Neuman (1982).

\subsection{STATISTICAL PARAMETER ESTIMATION METHOD}

In the past decade, a high level of sophistication has been achieved in the development of numerical techniques for simulating groundwater flow in aquifers. Before using a numerical model to calculate the steady-state hydraulic head distribution in a groundwater flow system, the aquifer parameters such as transmissivities, pumping and recharge rates, and boundary conditions must be known. However; there are usually insufficient measurements of aquifer properties and limited knowledge of recharge and pumping rates and boundary conditions to fully model the flow system. During the past few years, numerical models have been used for estimating aquifer characteristics by using past water-level data and estimates of the recharge and pumping rates and boundary conditions. The problem of estimating aquifer characteristics with the aid of a numerical model is referred to as "parameter estimation" or the "inverse problem."

Given boundary conditions, sources and sinks, and a conceptual model, the traditional approach for calibrating a steady-state groundwater flow model has been to modify the estimates of transmissivity by a trial-and-error procedure until the simulated hydraulic heads are reasonably close to the measured 


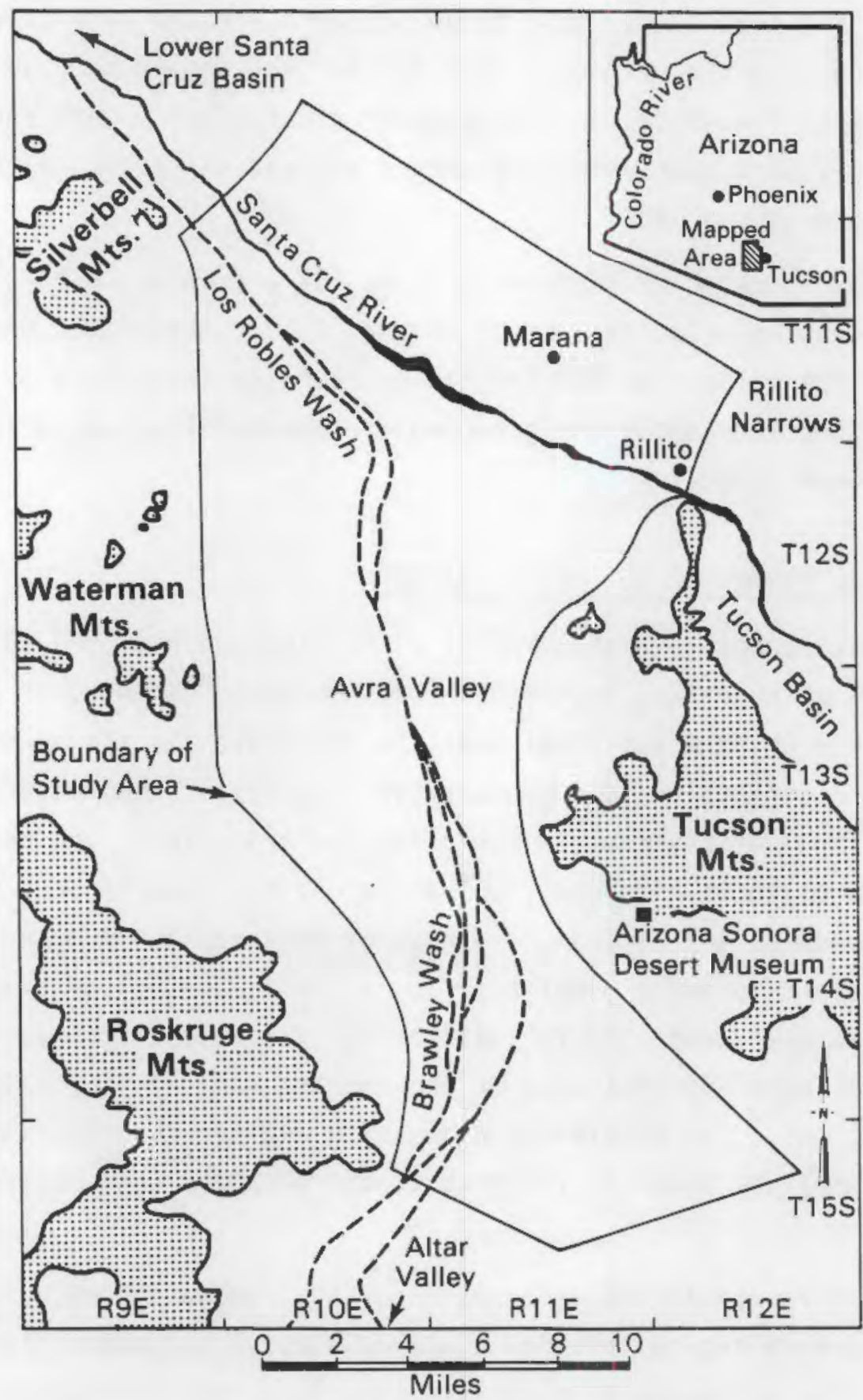

FIGURE 2.1. Location and Setting of Avra Valley, Arizona, and Study Area Boundary (from Clifton and Neuman 1982) 
hydraulic head data. Although such a trial-and-error procedure may yield a reasonable representation of the measured head data, the estimates of the transmissivity are not unique, and their associated uncertainty cannot be determined. To overcome these problems, a statistical parameter estimation method has been developed by Neuman (1980) for steady-state, two-dimensional groundwater flow problems.

The governing equation for steady-state, two-dimensional flow is written as:

$$
\nabla \cdot T \nabla h-q=0
$$

in the region $R$, subject to some known boundary conditions. In Equation (2.1), $h$ is hydraulic head, $T$ is transmissivity, $q$ is the sink term, and $\nabla$ is a twodimensional gradient operator. Discretizing Equation (2.1) using a finite element method yields a set of linear equations written in matrix form as:

$$
\underline{\underline{A}}(\underline{I}) \underline{h}=\underline{Q}
$$

where $A$ is a square matrix whose elements contain information about the grid and are functions of $I, Q$ is a vector containing the source and sink terms and boundary flux information at the nodal points, and $\underline{h}$ is the vector of hydraulic heads at the nodal points.

Neuman related the measured hydraulic head values, $\underline{h}^{*}$, to the true unknown values, $h_{t}$, by

$$
\underline{h}^{*}=\underline{h}_{t}+\underline{\varepsilon}
$$

where $\underline{\varepsilon}$ is a noise vector. The mean and variance of the noise vector are assumed to be given by

$$
E(\underline{\varepsilon})=0
$$




$$
\operatorname{Var}(\underline{\varepsilon})=q_{h}^{2} \underline{\underline{V}}_{h}
$$

where $V_{h}$ is a known positive-definite symmetric matrix, and $\frac{2}{h}$ is a positive scalar whose magnitude may, but need not, be known. The matrix $V_{h}$ and scalar $\frac{2}{h}$ can often be estimated by kriging, a geostatistical interpolation technique.

Neuman (1980) defined the statistical parameter estimation method in terms of the logarithm of the transmissivity; thus,

$$
Y=\log _{10} T
$$

One reason for defining the inverse problem in terms of $Y$ instead of $T$ is the guarantee that the transmissivities will always be positive. An additional reason is based on practical experience and the assumed log normal distribution of transmissivity. Further discussion of this point may be found in the paper by Neuman. The estimate of $\log$ transmissivity is the vector, $\underline{\hat{y}}$, that minimizes a compositive least squares criterion, $\mathrm{J}(\underline{\hat{Y}})$, given by

$$
J(\underline{\hat{Y}})=J_{h}(\underline{\hat{Y}})+\lambda J_{Y}(\underline{\hat{Y}})
$$

where $\lambda$ is a non-negative scalar. The criterion of model fit is defined by

$$
J_{h}(\underline{\hat{Y}})=\left[\underline{h}^{*}-\underline{A}^{-1}(\underline{\hat{Y}}) \underline{Q}\right]^{\prime} \underline{\underline{y}}_{h}^{-1}\left[\underline{h}^{*}-\underline{A}^{-1}(\underline{\hat{Y}}) \underline{Q}\right]
$$

and the criterion of parameter plausibility is defined as

$$
J_{Y}(\underline{\hat{Y}})=\left(\underline{Y}^{*}-\underline{\hat{Y}}\right)^{\prime} \underline{y}_{Y}^{-1}(\underline{Y} *-\underline{\hat{Y}})
$$


where $\underline{Y *}^{*}$ is a vector containing the prior estimates of log transmissivity and the prime (') indicates transpose of the vector. The prior estimates of $\underline{\gamma}^{\star}$ are related to the true unknown values, $\underline{Y}_{t}$, by

$$
\underline{Y} \underline{Y}^{*}=\underline{Y}_{t}+\underline{v}
$$

and $\underline{v}$ is a vector of random errors whose mean and covariance are given by

$$
\begin{aligned}
& E(\underline{v})=0 \\
& \operatorname{Var}(\underline{v})=q_{Y}^{2} \underline{\underline{v}}_{Y}
\end{aligned}
$$

The matrix $\underline{V}_{Y}$ is a known positive-definite symmetric matrix, and $\sigma_{Y}^{2}$ is a positive scalar whose magnitude may, but need not, be known. Again, $\underline{V}_{Y}$ and $\dot{\sigma}_{Y}^{2}$ can often be calculated by kriging. If $\sigma_{Y}^{2} \underline{V}_{Y}$ is known, the non-negative scalar $\lambda$ is related to $\operatorname{Var}(\underline{\varepsilon})=\sigma_{h}^{2} \underline{V}_{h}$. If $\sigma_{h}^{2} \underline{V}_{h}$ is completely known, then $\lambda$ must be set equal to $\sigma_{h}^{2}$, or $v_{h}$ in Equation (2.8) is replaced by $\sigma_{h}^{2} v_{h}$ and $\lambda$ is set equal to 1. For unknown $\sigma_{h}, \lambda$ is also unknown, and Equation (2.7) must be minimized for a range of $\lambda$ values. The optimum $\lambda$ value may be chosen as the value that corresponds to the best estimate of $\sigma_{h}^{2}$. A more detailed discussion of the minimization technique and method for choosing the optimum $\lambda$ value can be found in Neuman (1980). After the optimum solution for $\underline{\hat{y}}$ has been determined, the estimation error is defined as

$$
\underline{e}_{\gamma}=\underline{Y}_{t}-\underline{\hat{y}}
$$

whose expectation and covariance matrix are, respectively

$$
\begin{aligned}
& E\left(\underline{e}_{Y}\right)=0 \\
& \operatorname{Var}\left(\underline{e}_{Y}\right) \simeq q_{h}^{2}\left(\underline{\underline{z}}^{\top} \underline{\underline{v}}_{h}^{-1} \underline{\underline{z}}+\lambda \underline{\underline{v}}_{Y}^{-1}\right)^{-1}
\end{aligned}
$$


where $z$ is the sensitivity matrix whose elements are the derivatives of hydraulic head with respect to the log transmissivities. The covariance matrix, $\operatorname{Var}\left(\underline{e}_{Y}\right)$, reflects correlation between the $\log$ transmissivities in the various zones as well as the uncertainty in the inverse estimates of $10 \mathrm{~g}$ transmissivity.

Clifton and Neuman (1982) applied the statistical parameter estimation technique to the data from the Avra Valley aquifer. Kriged estimates of log transmissivities were used as prior information in the inverse model, together with known sources and sinks and boundary conditions. The observed values of hydraulic head at the nodal points were estimated from a hand-contoured hydraulic head map. An optimum solution for the inverse model was obtained by Clifton and Neuman, and the details of the procedure may be found in that paper. Figure 2.2 shows a contour map of the transmissivity estimates obtained from the means of log transmissivities, $\hat{Y}$, calculated using the inverse model. Figure 2.3 presents the corresponding contour map of 1 og transmissivity estimation errors. Figure 2.4 shows a comparison of the hydraulic heads computed from the inverse transmissivities to the 1940 steady-state hydraulic heads that were used as the observed head values in the inverse model. The hydraulic heads calculated from the inverse transmissivities are in close agreement with the estimates from the hand-contoured hydraulic head map.

The $\log$ transmissivities, $\hat{Y}$, that were obtained from the inverse method, together with the known boundary conditions, sources and sinks, and resulting hydraulic head distribution, constitute a statistically calibrated groundwater flow model of the Avra Valley aquifer. In addition, the estimate of the uncertainty of the $\log$ transmissivity is obtained from the covariance matrix $\operatorname{var}\left(\underline{e_{y}}\right)$. 


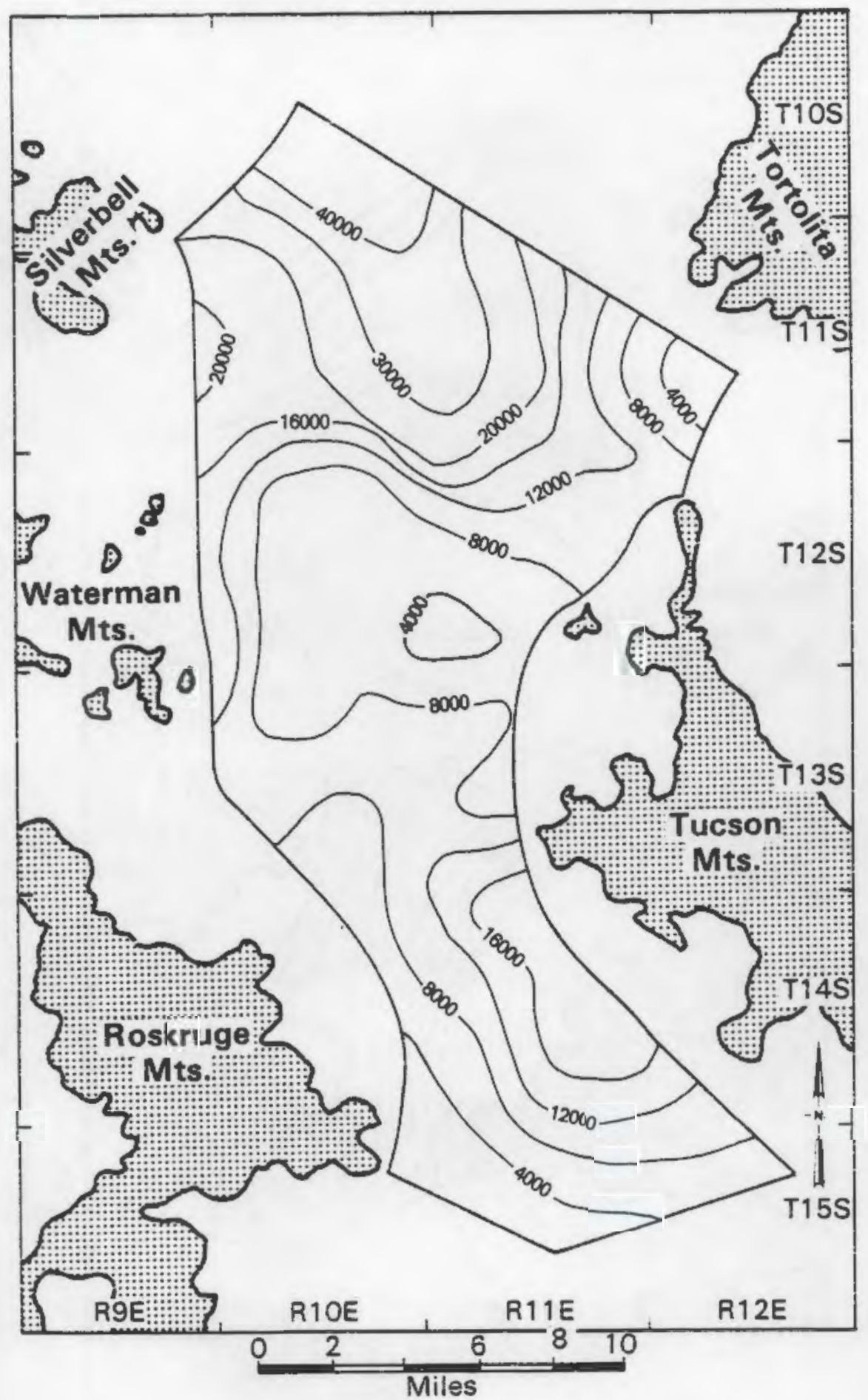

FIGURE 2.2. Contour Map of the Transmissivity Estimates from Log Transmissivities Obtained by Parameter Estimation Model (from Clifton and Neuman 1982) 


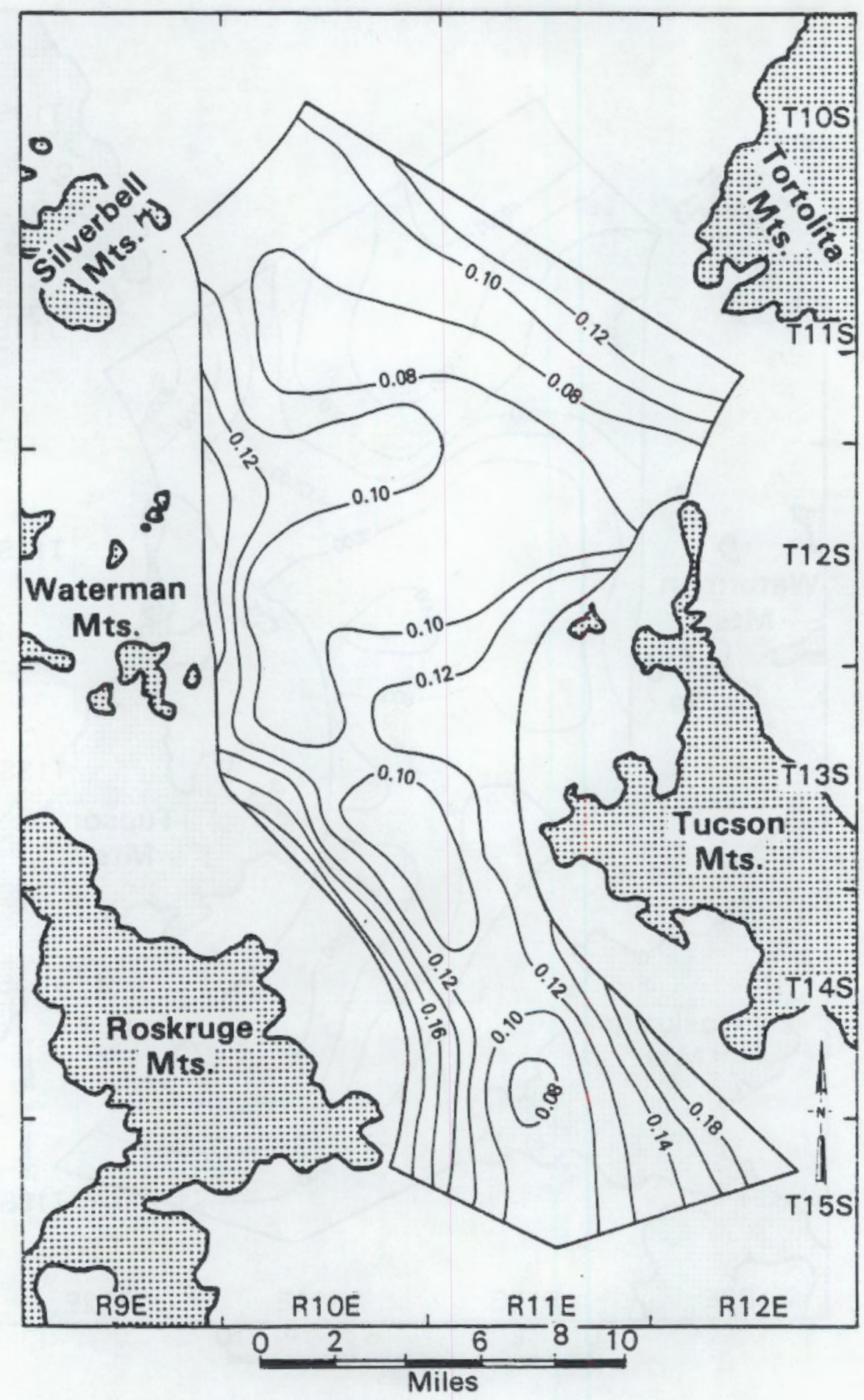

FIGURE 2.3. Contour Map of the Log Transmissivity Estimation Errors (from Clifton and Neuman 1982) 


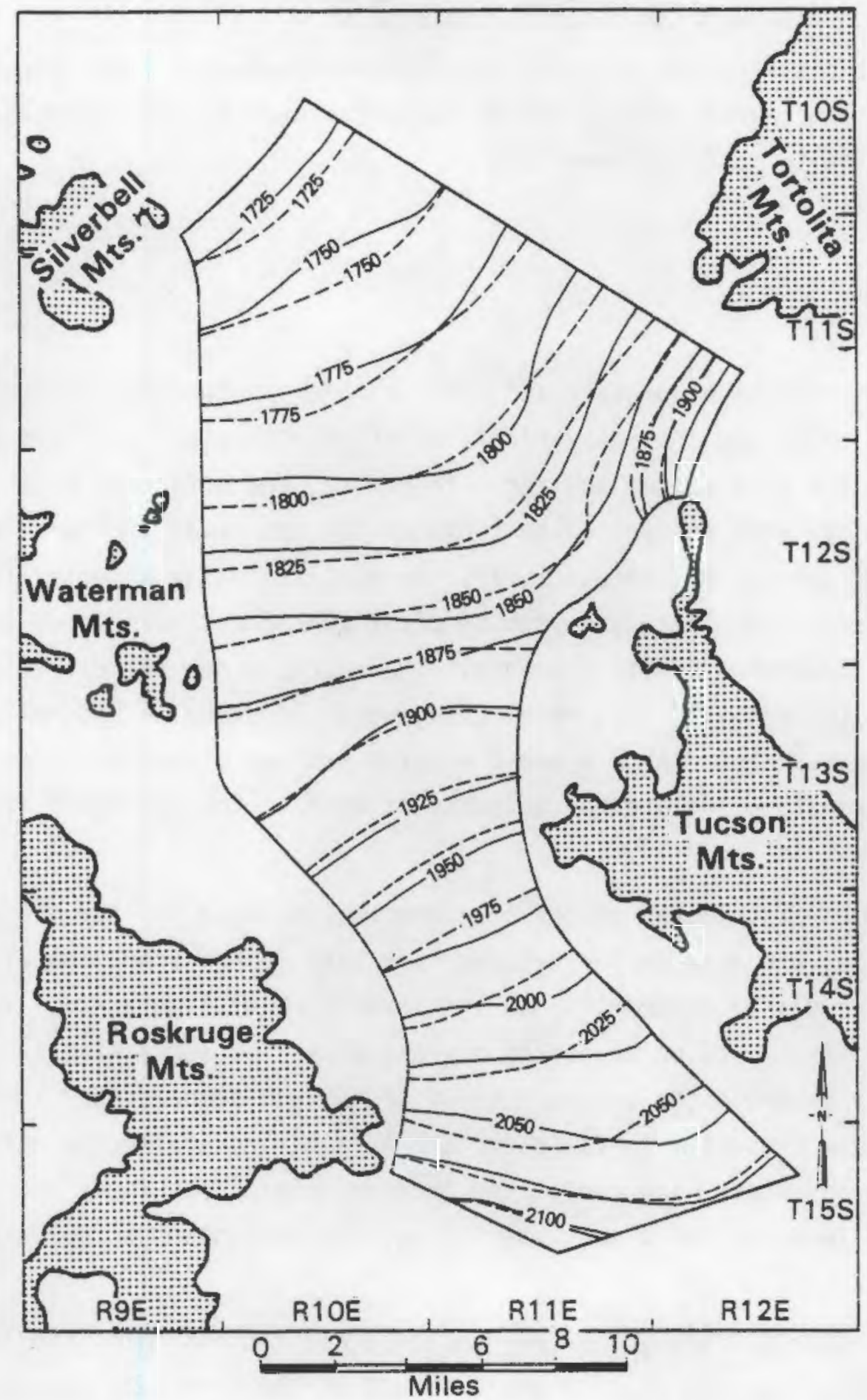

FIGURE 2.4. Comparison of the 1940 Steady-State Hydraulic Heads and the Heads Computed from Inverse Transmissivities (from Clifton and Neuman 1982) 


\subsection{PATHLINE AND CUMULATIVE OUTFLOW CALCULATIONS}

A spatial distribution of velocities for a groundwater flow system can be obtained from the transmissivity values and associated hydraulic heads. The pore-water velocity is calculated from

$$
\underline{v}=-\frac{T}{n b} \nabla h
$$

where $n$ is the effective porosity and $b$ the aquifer thickness. Limited data are available about the spatial variability of effective porosity and aquifer thickness for the Avra Valley aquifer. Therefore, the effective porosity and aquifer thickness were assumed to be constant for the study area and assigned values of 0.35 and $500 \mathrm{ft}$, respectively. In generating the velocity field, it became necessary to minimize the problem of discontinuous velocities at the boundaries of adjoining finite elements. Therefore, a new velocity field grid was formed on the original flow model grid, which is shown in Figure 2.5. The flow model solution and finite element basis functions (i.e., bilinear functions) were used to calculate the velocity at each of the new nodes of the velocity field grid.

The assumed distributed source of contamination used for the transport calculations for the Avra Valley aquifer is a line source approximately 4 miles long and is shown as a dotted line in the lower part of Figure 2.5. The contaminants are assumed to be deposited dry and mixed instantly with the groundwater, thereby entering the system without adding additional fluid to the system. Because the velocity field for the Avra Valley aquifer is calculated assuming a steady-state flow condition, the contaminant pathlines are identical to the streamlines for the flow system (i.e., the contaminants follow the streamlines).

For the velocity field, starting coordinate locations along the line source were calculated so that an equal amount of the flux (2\%) passed between adjacent streamlines. This spacing of locations gave a total of 51 contaminant starting points along the line source. Pathlines were generated from each of 


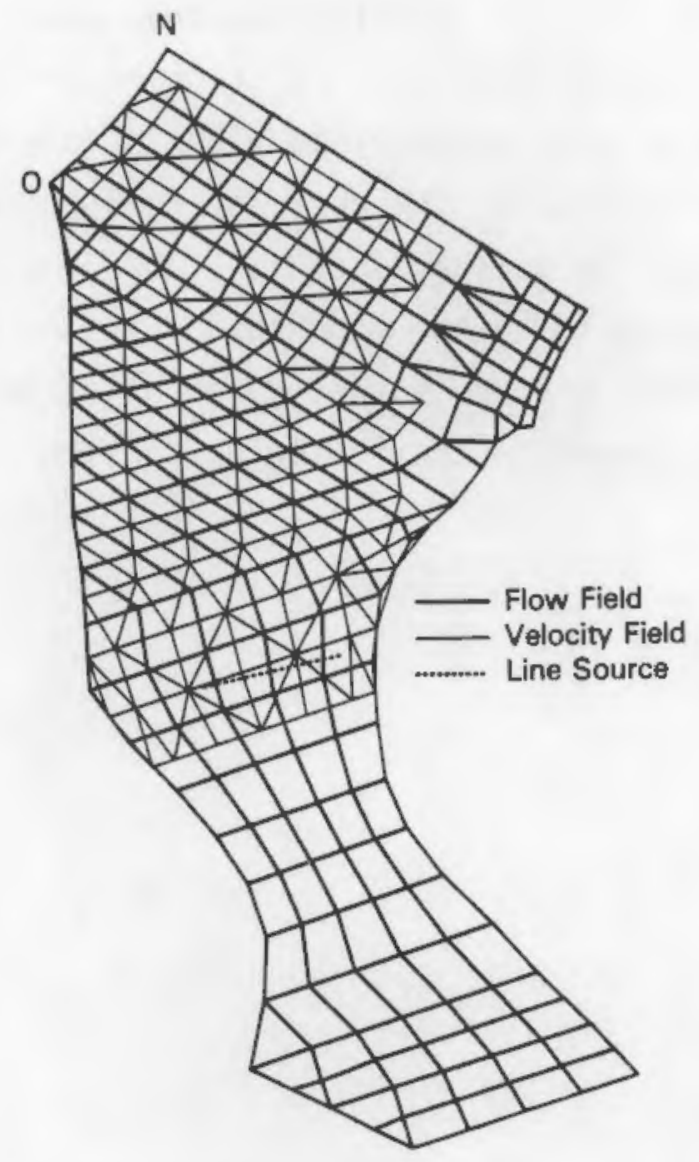

\section{FIGURE 2.5. Velocity Field Grid Imposed on} Avra Valley Flow Model Grid

the starting points along the line source to the outflow boundary denoted as $0-\mathrm{N}$ in Figure 2.5. In addition, the time it took the contaminant to arrive at the outflow boundary was determined for each pathline.

As mentioned previously, the pathlines are also streamlines because the flow is steady. A stream function is defined as constant along a streamline. The flux between two streamlines is proportional to the difference in the stream functions corresponding to these lines. The time of arrival of the contaminant at the outflow boundary can be plotted versus the stream function because an arrival time has been calculated for each streamline. Let $Q$ equal the total flux of contaminant and $q$ represent the amount that has crossed the 
outflow boundary at a given time. The relationship between stream function and contaminant arrival time is used to calculate the cumulative flux that has crossed the outflow boundary, $q / Q$, as a function of arrival time. Examples of cumulative outflow curves will be provided with the discussion in Section 4.2 . The details of the calculation of the curve of cumulative outflow versus arrival time can be found in Nelson, Jacobson, and Conbere (1985). The uncertainty in this curve produced by the uncertainty of $10 \mathrm{~g}$ transmissivity calculated by the inverse model will be investigated using the three uncertainty techniques that are discussed in the following section. 


\subsection{DESCRIPTION OF UNCERTAINTY ANALYSIS METHODS}

Applying the parameter estimation method to the Avra Valley aquifer produces estimates of the mean and the covariance matrix of log transmissivity, $\underline{\underline{y}}$ and $\operatorname{Var}\left(\underline{e}_{y}\right)$, respectively. These mean log transmissivity estimates, together with the known boundary conditions and sources and sinks, yield a calibrated groundwater flow model for the Avra Valley aquifer. In this case, uncertainty in the travel time for a contaminant to reach an outflow boundary is assumed to be caused solely by uncertainty in the log transmissivity. The travel times are calculated from the calibrated groundwater flow model together with a transport model. The uncertainty of the travel time can be quantified by using the mean and covariance matrix of the log transmissivity in various uncertainty techniques that are applied to transport models. In this section, three uncertainty methods 1) Monte Carlo simulation with unconstrained sampling, 2) Monte Carlo simulation with Latin Hypercube sampling, and 3) first-order method are described as they apply to the hydrologic modeling of the Avra Valley aquifer.

\subsection{MONTE CARLO SIMULATION WITH UNCONSTRAINED SAMPLING}

Monte Carlo simulation involves generating a large number of realizations of transmissivity and solving the groundwater flow problem for each realization. The travel times corresponding to each realization represent sample data from which the probability density function, mean, and variance of the model output can be estimated. Unconstrained Monte Carlo sampling uses the log transmissivity mean vector and the covariance matrix obtained from the parameter estimation technique to generate realizations of $\log$ transmissivity.

A realization of $\log$ transmissivity, $\underline{y}$, is obtained from the following equation:

$$
\underline{\underline{Y}}=\underline{\hat{Y}}+\underline{e_{Y}}
$$


where $\hat{\underline{Y}}$ is a vector of means of $\log$ transmissivity, and $\underline{e}_{y}$ is a vector representing random errors with $E\left(\underline{e}_{\gamma}\right)=0$. Thus, the statistical properties of the realizations are

$$
E(\underline{Y})=\underline{\hat{Y}}
$$

and

$$
\operatorname{Var}(\underline{y})=\operatorname{Var}\left(\underline{e}_{Y}\right)=\underline{y}
$$

Because $\log$ transmissivity is assumed to be a normally distributed variable, Clifton and Neuman (1982) suggested generating a log transmissivity realization with the statistical properties given above by first generating a realization, $\underline{x}$, of another random vector having the normal distribution, $N(0, I)$, where $\underline{I}$ is the identity matrix. The $\underline{x}$ vector is obtained using a univariate normal random number generator. The realizations of log transmissivity are obtained by setting

$$
\underline{Y}=\underline{\hat{Y}}+\underline{\underline{M}} \underline{X}
$$

where $\stackrel{M}{=}$ is a lower triangular matrix defined as

$$
\underline{\underline{M}} \underline{\underline{M}}^{\prime}=\underline{\underline{V}}
$$

The $M$ matrix is obtained by a Cholesky decomposition of $\underset{=}{\underline{V}}$. The transmissivity values are then obtained from

$$
T=10^{Y}
$$




\subsection{MONTE CARLO SIMULATION WITH LATIN HYPERCUBE SAMPLING}

The difference between Monte Carlo simulation with Lat in Hypercube sampling and Monte Carlo simulation with unconstrained sampling is the method used to select the values of the model input variables. The Lat in Hypercube method of sampling, first proposed by McKay, Conover, and Beckman (1979) to efficiently select values of input variables for performing sensitivity analyses for complex computer codes, gets its name from a statistical experimental design called the Latin Square (Kempthorne 1952). The concept of the Latin Square is also used in the context of statistical sampling as a way to stratify populations to reduce the variance of the estimates of the characteristics of interest (Cochran 1963).

Latin Hypercube sampling is a generalization of Latin Square sampling to $K$ dimensions, which correspond to the number of input variables of the model. Each input variable is assumed to be a random variable governed by a probability density function. (Input variables that are constants can be described by a degenerate probability density function.) The stratification is accomp1 ished by dividing the range of the input variable into $N$ intervals of equal $(1 / N)$ probability. An example of a probability density function is shown in Figure 3.1. The vertical partitions of the function represent intervals that have the same probability of occurring $(1 / N)$. Each equiprobable interval is randomly sampled once for each variable. The output of the sampling can be considered an $\mathrm{N} \times \mathrm{K}$ matrix, where the columns represent variables and the rows contain the sample values for the appropriate interval. The values within a column are then randomly permuted so that a row of the $N \times K$ matrix, $Y$, represents a random vector of the input variables. The computer model is then run $N$ times with the values of the input variables equal to the rows of the matrix.

Advantages of Latin Hypercube sampling over unconstrained sampling methods are that it provides:

- an efficient method for sampling the entire range of each variable in accordance with the assumed probability density function

- estimates of the mean, variance, and probability density function of the model output variables that will have smaller variances. 


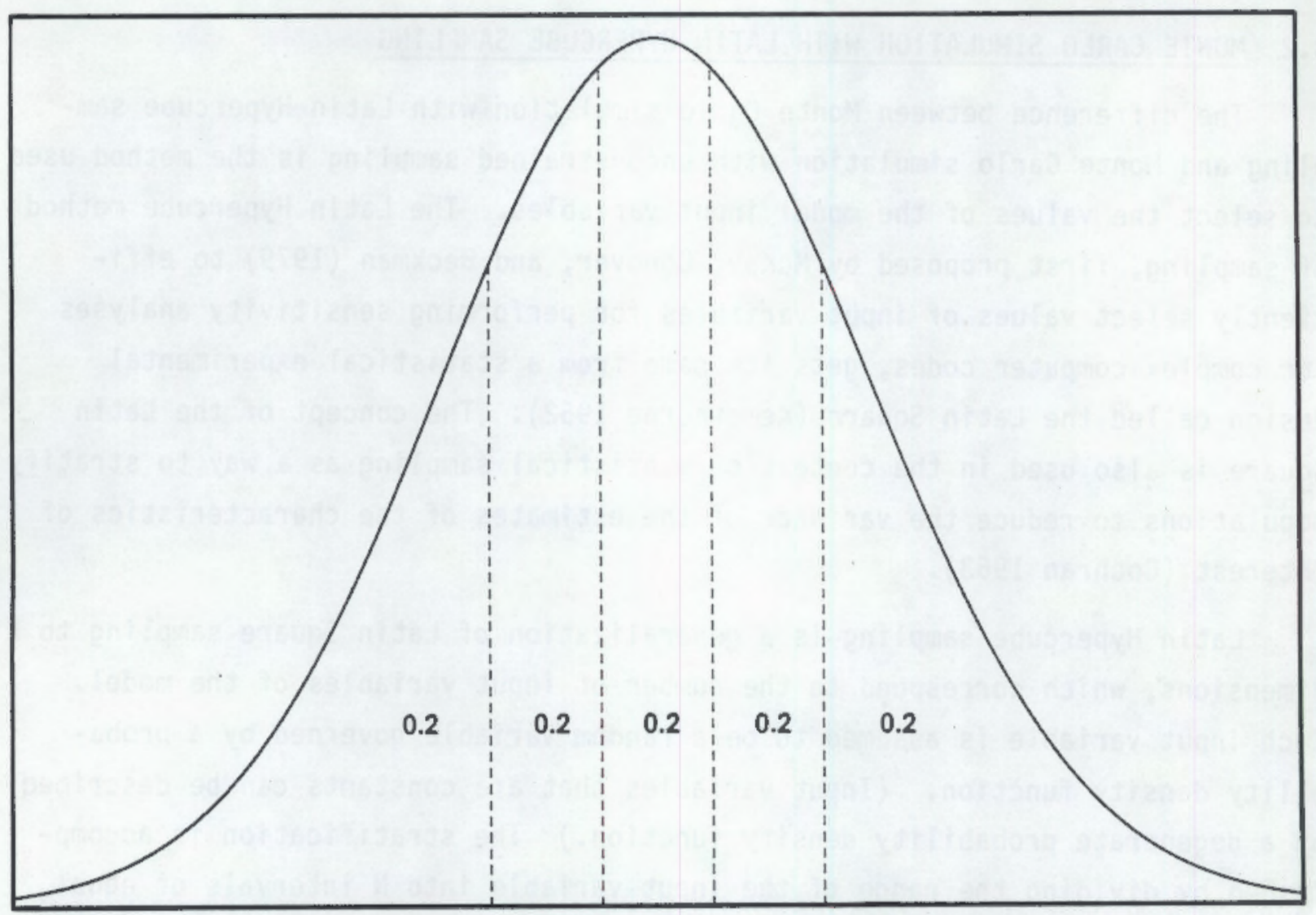

FIGURE 3.1. Example of Probability Density Function Divided into Equiprobable Intervals (after Iman and Shortencarier 1984)

The reduction in variance of the estimates is a result of the stratification of the probability density function.

When Latin Hypercube sampling was first proposed, the input variables were assumed to be independent. However, in many models the input variables are clearly not independent, and the dependencies can be highly nonlinear. Iman and Conover (1982) developed a method for inducing dependencies among the variables using rank correlation. Dependencies among random variables are described by a bivariate correlation coefficient; higher order dependencies are difficult to deal with in practice. The Pearson product moment correlation coefficient for random variables $Y_{i}$ and $Y_{j}$, given as 


$$
\rho_{P}=\frac{\operatorname{Cov}\left(Y_{i}, Y_{j}\right)}{\left[\operatorname{Var}\left(X_{i}\right) \operatorname{Var}\left(Y_{i}\right)\right]^{1 / 2}}
$$

is commonly used to quantify the degree of dependence; however, it is meaningful for only linear relationships and the normal probability distribution. Iman and Conover concluded that most dependencies, even the ones that are highly nonlinear, are monotonically nondecreasing or nonincreasing over some range of values. The Spearman rank correlation coefficient

$$
\rho_{S}=\frac{\operatorname{Cov}\left[R\left(Y_{j}\right), R\left(Y_{j}\right)\right]}{\left\{\operatorname{Var}\left[R\left(Y_{j}\right)\right] \operatorname{Var}\left[R\left(Y_{j}\right)\right]\right\}^{1 / 2}}
$$

which is the Pearson product moment correlation coefficient computed on the ranks $R\left(Y_{j}\right)$ of the data, measures the degree of monotonicity between random variables. Iman and Conover devised a method of using bivariate rank correlations to induce the desired dependencies among random variables while maintaining the desired univariate probability distributions obtained with the original Latin Hypercube sample.

The method for inducing dependencies among the variables is based on the Cholesky decomposition of the desired rank correlation matrix to generate a restricted pairing of the elements of the columns of the Latin Hypercube sample matrix $Y$. The specific values of the variables generated by the Latin Hypercube sampling method described earlier are not changed, but they are paired in such a way to induce the desired dependencies anong the variables.

Assume, as before, that there are $K$ input variables and $N$ intervals per variable. The random matrix, $Y$, consisting of $N$ observations of $K$ independent variables, is obtained by the Latin Hypercube sampling algorithm explained above. By the construction of the Latin Hypercube sample, $Y$ theoretically has rank correlation matrix I (identity matrix), that is, the $k$ "variables are independent. Let $\underset{=}{C}$ be the desired rank correlation matrix. Because $\underset{c}{C}$ is $a$ 
symmetric positive definite matrix, it can be decomposed into the product of a lower triangular matrix with its transpose

$$
\cong=P_{=}^{P}{ }^{\prime}
$$

Let matrix $R$ be the matrix of scores, $a_{j}$, resulting from the rankings of the columns of $y_{=}$. The scores used by Iman and Conover are van der waarden scores

$$
a_{i}=\phi^{-1}[\mathbf{i} /(N+1)]
$$

where $\phi^{-1}$ is the inverse of the standard normal probability density function and $i$ is the rank of the element in the column. Let $R^{\star}$ be the matrix of scores after selective pairings of the elements of the columns of $R$. The objective is to have the Spearman rank correlation matrix, $R^{\star}$, close to the desired rank correlation matrix $\underset{=}{C}$. If the rank correlation matrix, $U$, of every realization of $R$ were exactly the identity $I$, then the Cholesky decomposition given in Equation (3.9) could be used directly. However, because $R$ is a random matrix, the sampling variation for any realization of $R$ will produce a rank matrix, $U$, which only approximately equals $\stackrel{I}{=}$. Therefore, $=$ plied by a matrix, $\stackrel{S}{=}$, so that

$$
\underline{\underline{S}} \underline{\underline{\underline{S}}} \underline{\underline{S}}^{\prime}=\underline{\underline{C}}
$$

To find $S$, the Cholesky decomposition, $\underset{=}{U}=\underline{Q Q}_{=}^{\prime}$, is performed. (U must be positive definite, so $R$ must not contain identical columns.) Therefore, substituting Equation (3.9) in Equation (3.11) yields the following:

$$
\underline{\underline{S} \underline{\underline{Q}} \underline{Q}^{\prime}} \underline{\underline{S}}^{\prime}=\underline{\underline{P}} \underline{\underline{P}}^{\prime}
$$

and

$$
\underline{S}=\underline{P Q}^{-1}
$$


Then

$$
\stackrel{R}{*}^{\star}=\underline{R}^{\prime}
$$

The elements of the columns of $Y$ are then rearranged according to the ranking matrix, $R^{\star}$, to produce a new Latin Hypercube sample matrix, $Y^{\star}$, which has a rank correîtion matrix close to the desired $\mathbf{C}$.

The method for inducing dependencjes in the Latin Hypercube sample uses the rank correlations of the input variables. However, the output of the statistical parameter estimation technique is a covariance matrix. Because it is assumed in the application of the statistical parameter estimation technique that the logarithm of transmissivity is normally distributed, a Pearson product moment correlation matrix can be produced by dividing each element of $V$ by the square root of the appropriate diagonal elements [Equation (3.7)]. Because multivariate normal variables can only be linearly related, the rank and Pearson correlation coefficients, although not identical algebraically, produce similar values. Therefore, the Pearson correlation coefficients obtained from the covariance matrix of the statistical parameter estimation method can be used as rank correlation coefficients to generate the desired dependence structure in the realizations of the spatial distribution of log transmissivity using Latin Hypercube sampling.

\subsection{FIRST-ORDER METHOD}

The first-order method to uncertainty analysis that is applied to groundwater travel time is based on a Taylor series expansion of travel time about the mean values of $\log$ transmissivity. The Taylor series expansion for travel time, $\mathrm{Tr}$, can be written as

$$
\operatorname{Tr}(\underline{Y})=\operatorname{Tr}(\underline{\hat{Y}})+\sum_{\mathbf{i}} \frac{\partial T r}{\partial Y_{i}}\left(Y_{i}-\hat{Y}_{\mathbf{i}}\right)+\ldots
$$


where the mean $\log$ transmissivity is the vector $\hat{y}$. The first-order method neglects terms in the series expansion that involve second-order or higher partial derivatives.

The equations for the mean and variance of the groundwater travel time are obtained from the first-order expression of the series expansion and are written respectively as

$$
\begin{aligned}
E(T r)= & \operatorname{Tr}(\hat{Y}) \\
\operatorname{Var}(T r)= & \sum_{j} \frac{\partial T r^{2}}{\partial Y_{i}} \operatorname{Var}\left(Y_{j}\right) \\
& +\sum_{j} \sum_{j} \frac{\partial T r}{\partial Y_{j}} \frac{\partial T r}{\partial Y_{j}} \operatorname{Cov}\left(Y_{i}, Y_{j}\right) \\
& i \neq j
\end{aligned}
$$

where $\operatorname{Cov}\left(Y_{j}, Y_{j}\right)$, the covariance between $Y_{i}$ and $Y_{j}$, is the $i, j$ th element of the covariance matrix $V$. The mean travel time is easily calculated from the calibrated groundwater flow model, which uses the mean log transmissivity values, $\hat{y}$. The first partial derivatives of travel time with respect to the log transmissivities and the covariance matrix, $\underset{=}{V}$, are needed to calculate the variance of travel time.

The first partial derivatives of travel time can be estimated by varying the $\log$ transmissivities one at a time and calculating the corresponding travel times. A finite difference approximation to the partial derivative is given by

$$
\frac{\partial T r}{\partial Y_{i}}=\frac{T r_{1}-T r_{2}}{Y_{i 1}-Y_{i 2}}=\frac{\Delta T r}{\Delta Y_{i}}
$$

where subscripts 1 and 2, respectively, correspond to the values of $Y_{i}$ at positive and negative variations that are symmetric about the mean value. Variations equal to $5 \%$ of the standard deviation of $\log$ transmissivity are used for 
each $\log$ transmissivity. After the partial derivatives are obtained, the variance of travel time can be calculated from the mathematical expression given in Equation (3.17).

This application of the first-order method differs from the adjoint firstorder method suggested by Harper and Gupta (1983) in the calculation of the partial derivatives. They have suggested using the adjoint technique to ootain more accurate estimates of the partial derivatives. The second-order method suggested by Sagar and clifton (1985) includes the second-order terms (i.e., second partial derivatives) in the Taylor series expansion. 


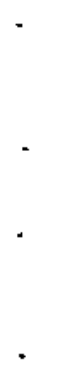




\subsection{COMPARISON OF RESULTS FROM UNCERTAINTY ANALYSIS METHOOS}

The purpose of this report is to investigate the ability of the three uncertainty analysis methods described in Section 3.0 to generate estimates of uncertainty for the travel time output of the hydrologic flow model. Therefore, for this investigation, the basis of comparison will be the direct (sample) estimates of the mean, standard deviation, correlation coefficient and probability density function of the input and output variables for the Monte Carlo methods. Because the first-order method produces only estimates of the travel time, mean, and variance, its comparison with the Monte Carlo methods is based on output only.

Using the $\log$ transmissivity mean vector and covariance matrix described in Section 2.0, realizations were generated by the unconstrained sampling method described in Section 3.1. Because of the small amount of computer time needed to run the flow models for this particular application, the number of realizations generated by unconstrained sampling was set at 600 . Based on the stability of the simulation results, 600 realizations were deemed adequate for this modeling case.

The number of realizations, $N$, of the input variables generated by Latin Hypercube sampling must be at least equal to $K$, the number of input parameters. For the Avra Valley flow model, $K$ is 122 . To investigate the effect of the number of realizations of the input variables on the distribution of the output variable, Latin Hypercube samples of $N=125$ and $N=600$ were produced. Thus, three Monte Carlo simulations were made, two with Latin Hypercube sampling and one with unconstrained sampling.

The computer code used to generate the Lat in Hypercube samples was provided by R. L. Iman; the manual for the code is the reference, Iman and Shortencarier (1984). The computer code used to generate the unconstrained sampling and the groundwater flow simulations was obtained from S. P. Neuman at the University of Arizona and was used for the research reported by Clifton and Neuman (1982). The computer codes used to calculate the velocity field and cumulative outflow curves were developed by $W$. Conbere of PNL for the work reported in NeTson, Jacobson, and Conbere (1985). 


\subsection{COMPARISON OF THE INPUT VARIABLE DISTRIBUTIONS FOR MONTE CARLO METHODS}

The input parameters to all three of the Monte Carlo simulations (two Latin Hypercube simulations and one unconstrained sampling simulation) and the first-order analysis were the mean vector and covariance matrix of log transmissivity produced by the statistical parameter estimation method described in Section 2.0. Because the Pearson correlation coefficients were used as rank correlation coefficients in generating realizations of log transmissivity by the Latin Hypercube method, it is necessary to show that the technique used for inducing dependencies in Latin Hypercube sampling produced the same statistical structure in the realizations as the unconstrained sampling method that is described in Section 3.1. The realizations of $\log$ transmissivity for the three Monte Carlo simulations were compared on three criteria:

- closeness of the sample means of each input variable for each simulation to the mean parameter value produced by the statistical inverse

- closeness of the sample standard deviations of each input variable for each simulation to parameter standard deviation from the covariance matrix

- closeness of the sample Pearson correlation coefficients for each pair of input variables to the parameter Pearson correlation coefficients computed from the covariance matrix.

To show the results of these comparisons in concise form, the differences between the sample mean, standard deviation, correlation coefficient, and their corresponding parameter values are displayed in cumulative frequency histogram form. The histograms for the three simulations are plotted on the same figure to facilitate the comparison. Figure 4.1 illustrates the cumulative frequency histograms for the differences between the sample and parameter means. The horizontal axis is the difference, from negative to positive, of the sample and parameter means, and the vertical axis is the percentage of the 122 transmissivity variables with differences less than the value on the horizontal axis. 


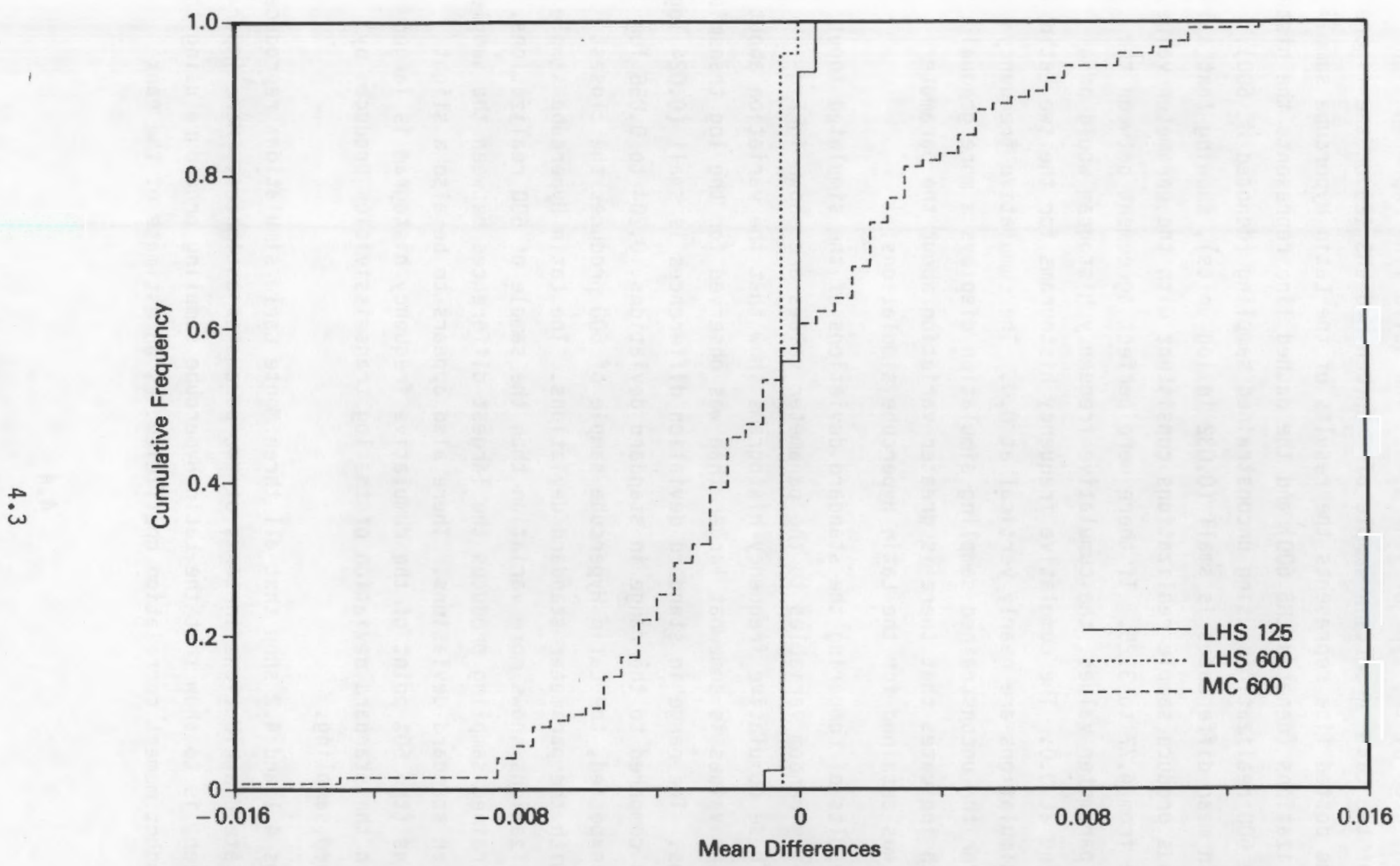

FIGURE 4.1. Cumulative Frequency Histograms of Differences Between Simulation Sample Transmissivity Means and Input Parameter Values 
The cumulative frequency histograms for the three Monte Carlo simulations are differentiated by the type of line used. The solid line represents the histogram of the Latin Hypercube sample of 125 (denoted LHS 125 on the figure legend), the dotted line represents the results of the Lat in Hypercube sample of 600 realizations (denoted LHS 600 ) and the dashed line represents the histogram of the 600 realizations using unconstrained sampling (denoted MC 600 ). The range in mean differences is small ( 0.032 in log units), showing that all three methods produce sample realizations consistent with the parameter values, which range from 4.77 to 3.25 . If there were perfect agreement between the sample and parameter values, the cumulative frequency histogram would be a vertical line at 0.0 . The cumulative frequency histograms for the two Latin Hypercube simulations are nearly vertical at 0.0 . The cumulative frequency histogram for the unconstrained sampling simulation displays a more gradual slope, which indicates that there is greater variation about the parameter means than was obtained for the Latin Hypercube simulations.

The results of comparing the standard deviations of the simulated input transmissivity random variables to the parameter values are shown in Figure 4.2. These cumulative frequency histograms show that the variation about the parameter values is somewhat larger than was observed for the log transmissivity means. The $\dot{r}$ ange in standard deviation differences is small $(0.024 \mathrm{log}$ units) when compared to the range in standard deviations, 0.204 to $0.05610 \mathrm{~g}$ units. As expected, the Latin Hypercube sample of 600 produces the closest agreement with the parameter standard deviations. The Latin Hypercube sample of 125 realizations shows more variation than the sample of 600 realizations. The unconstrained sampling produces the largest differences between the sample and parameter standard deviations. There also appears to be also a slight positive bias (the $50 \%$ point of the cumulative frequency histogram is larger than 0.0 ) in the standard deviation of the $\log$ transmissivities produced by unconstrained sampling.

Figures 4.1 and 4.2 show that all three Monte Carlo simulations reproduce the univariate distributions in terms of the parameter estimates. More important, however, is to show that the Latin Hypercube sampling procedure using the Pearson product moment correlation coefficient as an estimate of the rank 


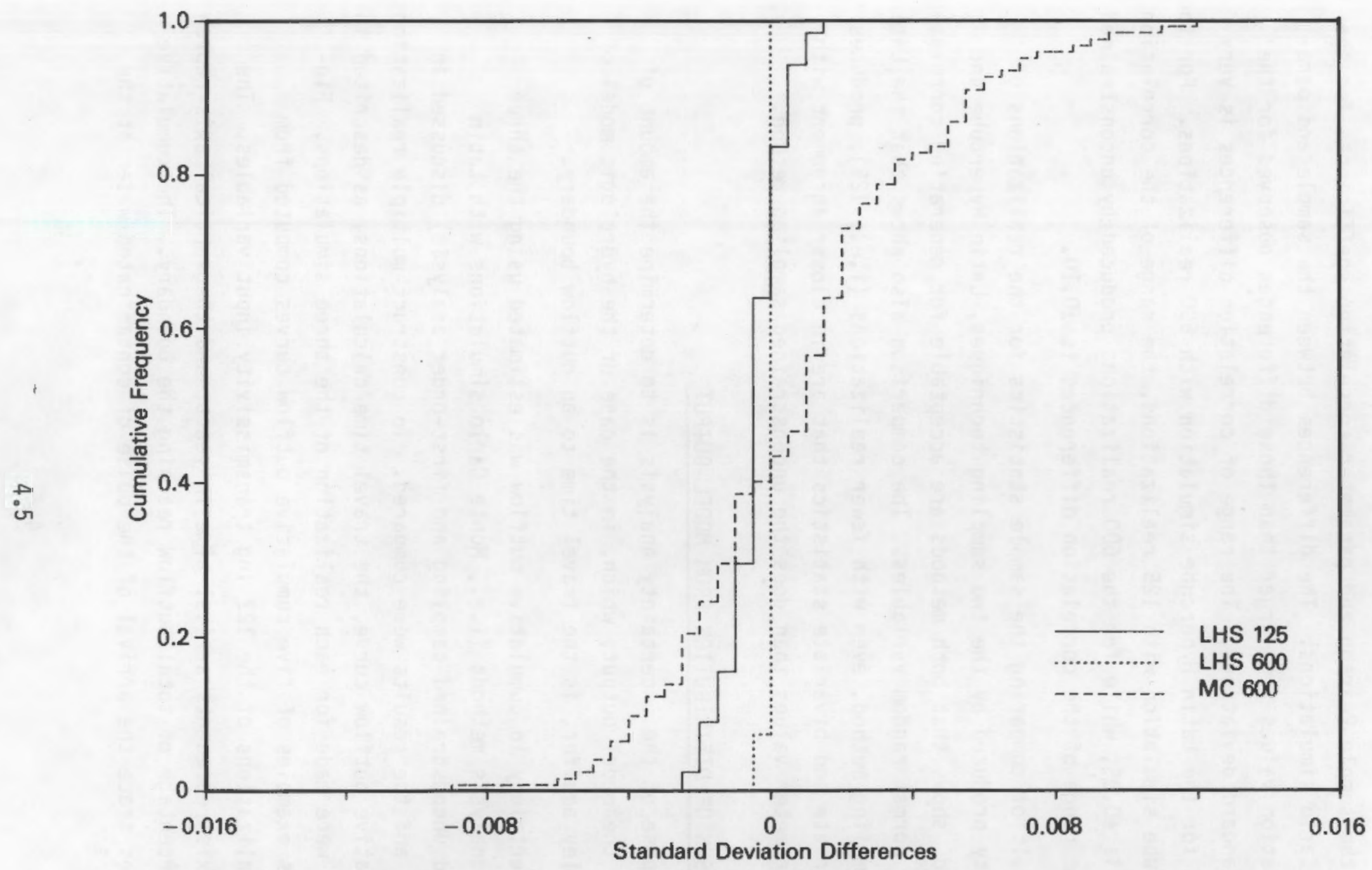

FIGURE 4.2. Cumulative Frequency Histograms of Differences Between Simulation Sample Transmissivity Standard Deviations and Input Parameter Values 
correlation coefficient produces the desired dependency among the input transmissivities. Figure 4.3 shows the cumulative frequency histograms of the differences of the sample Pearson and parameter correlation coefficients for the three Monte Carlo simulations. The differences between the sample and parameter correlation values are larger than those differences observed for the means and standard deviations. The range of correlation differences is very close to 0.0 for the Latin Hypercube simulation with 600 realizations. For the Latin Hypercube simulation with 125 realizations, the range of the correlation differences is \pm 0.05 , while for the 600 realizations produced by unconstrained sampling, the range of the correlation differences is \pm 0.10 .

The result of comparing the sample statistics for the realizations of transmissivity produced by the two sampling techniques, Latin Hypercube and unconstrained, shows that both methods are acceptable for generating correlated multivariate normal random variables. The comparison also shows that the Latin Hypercube sampling method, even with fewer realizations (i.e., 125), produces sample univariate and bivariate statistics that are in closer agreement with the input parameter values than does the unconstrained sampling method.

\subsection{COMPARISON OF DISTRIBUTION FROM MODEL OUWPUT}

The purpose of the uncertainty analysis is to determine the amount of variation in the model output, which, in the case of the hydrologic model of the Avra Valley aquifer, is the travel time to an outflow boundary.

The uncertainty in cumulative outflow was estimated using the three uncertainty analysis methods (i.e., Monte Carlo simulations with Latin Hypercube and unconstrained sampling and first-order analysis) discussed in Section 3.0, and the results were compared. To construct multiple realizations of the cumulative outflow curve, the travel time calculations, as described in Section 2.0, were made for each realization of the three simulations. Figure 4.4 shows examples of five cumulative outflow curves computed from different realizations of the $122 \mathrm{log}$ transmissivity input variables. The horizontal axis represents arrival time in years, and the vertical axis represents the percentage of total outflow reaching the boundary. The cumulative outflow curves trace the arrival of the pulse of contaminated water at the 


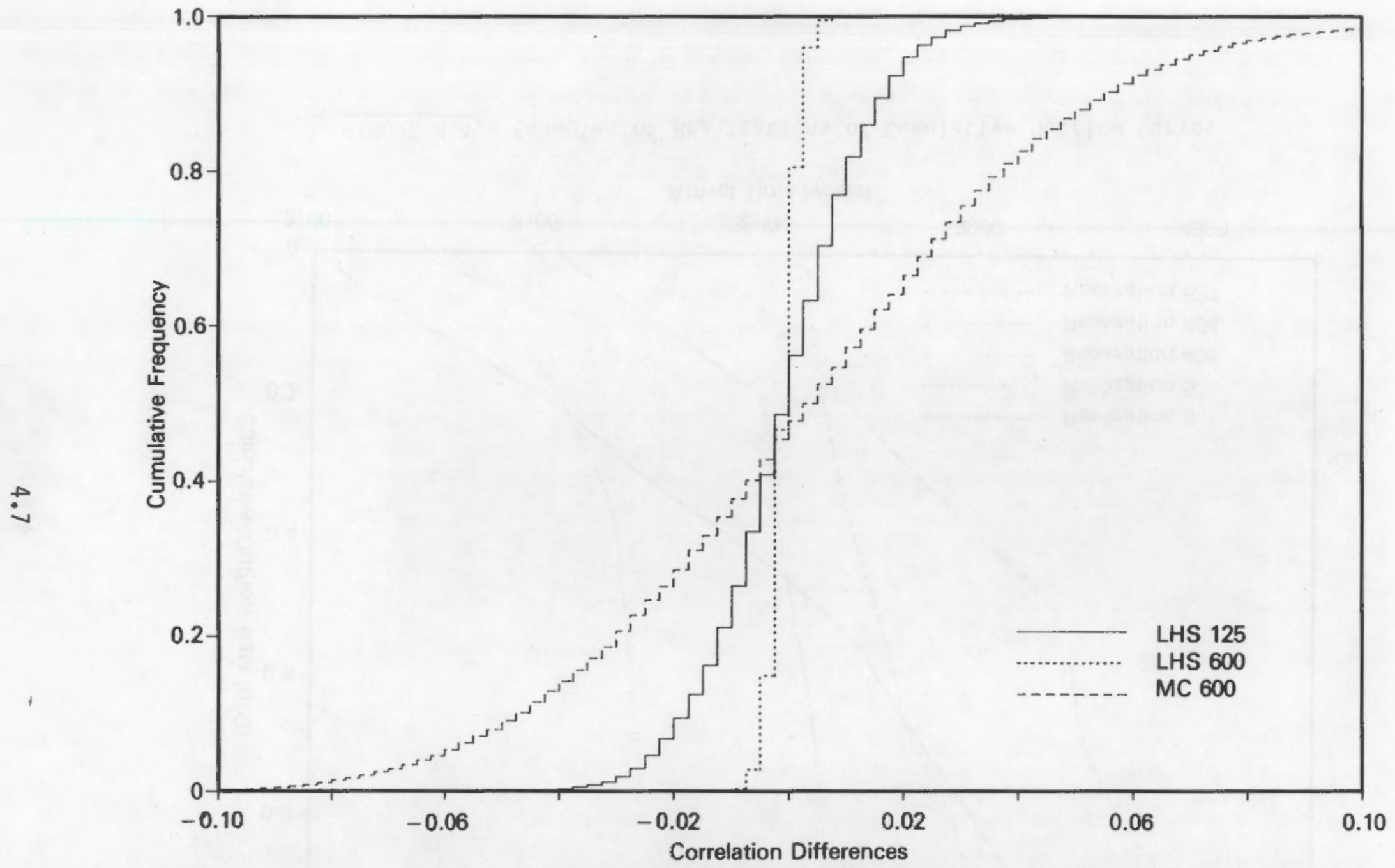

FIGURE 4.3. Cumulative Frequency Histograms of Differences Between Simulation Sample Transmissivity Pearson Product Moment Correlation Coefficients and Input Parameter Values 


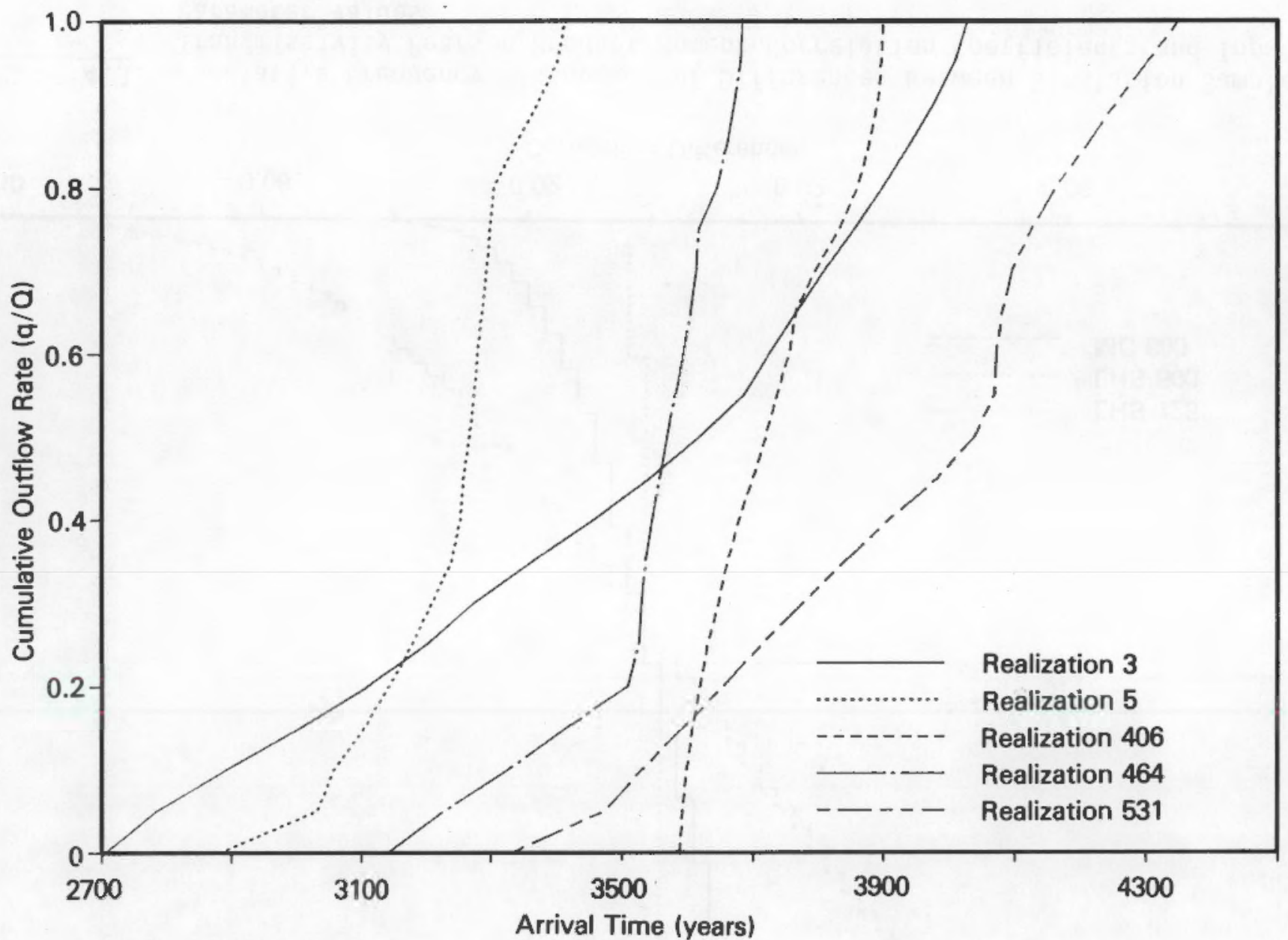

FIGURE 4.4. Examples of Realizations of Cumulative Outflow Curves 
outflow boundary. These realizations are from the unconstrained sampling simulation, but they are also representative of the Latin Hypercube realizations. The numbers in the legend of the figure refer to the order in which they were generated. These cumulative outflow curves show the diverse travel-time behavior that can result from the statistical variation in hydrologic modeling. Realization 406 represents one extreme - it takes a relatively long time for any contaminant from the pulse to reach the outflow boundary, but when it does, the entire amount of contaminant arrives in 200 years. Realization 3 is the other extreme - its first arrival of contaminated water occurs early, at 2700 years, but then it takes over 1300 years for all of the water to arrive at the outflow boundary.

Although the individual cumulative outflow curves demonstrate a variety of behaviors, it is useful to describe the variation statistically. The range of total outflow was divided into 21 intervals, from 0.0 (first arrival) to 1.0 $(100 \%)$ in increments of 0.05 . The arrival time for each realization in the simulation corresponding to the appropriate cumulative outflow interval can be considered a population. For the simulations with 600 realizations, there are 600 arrival times for each cumulative outflow interval and 125 arrival times in each interval for the simulation with 125 realizations. The cumulative frequency histograms for each cumulative outflow interval were produced for the three Monte Carlo simulations to determine the form of the probability distribution. The cumulative frequency histograms for the first arrival-time (zero flux) interval for the three simulations agree very closely and are shown in Figure 4.5. They show the classic behavior of a normal distribution (determined by a statistical test), which is somewhat unexpected since there has been some indication that travel times may be lognormally distributed ( $\mathrm{Cl}$ ifton, Baca and Arnett 1983).

For completeness, cumulative frequency histograms for each cumulative outflow interval were computed for the three Monte Carlo simulations. They are given in the appendix. These histograms show the same behavior as the histograms for the first arrival time, although the regions where the agreement is closest varies somewhat from the center of the distribution to the extremes. 


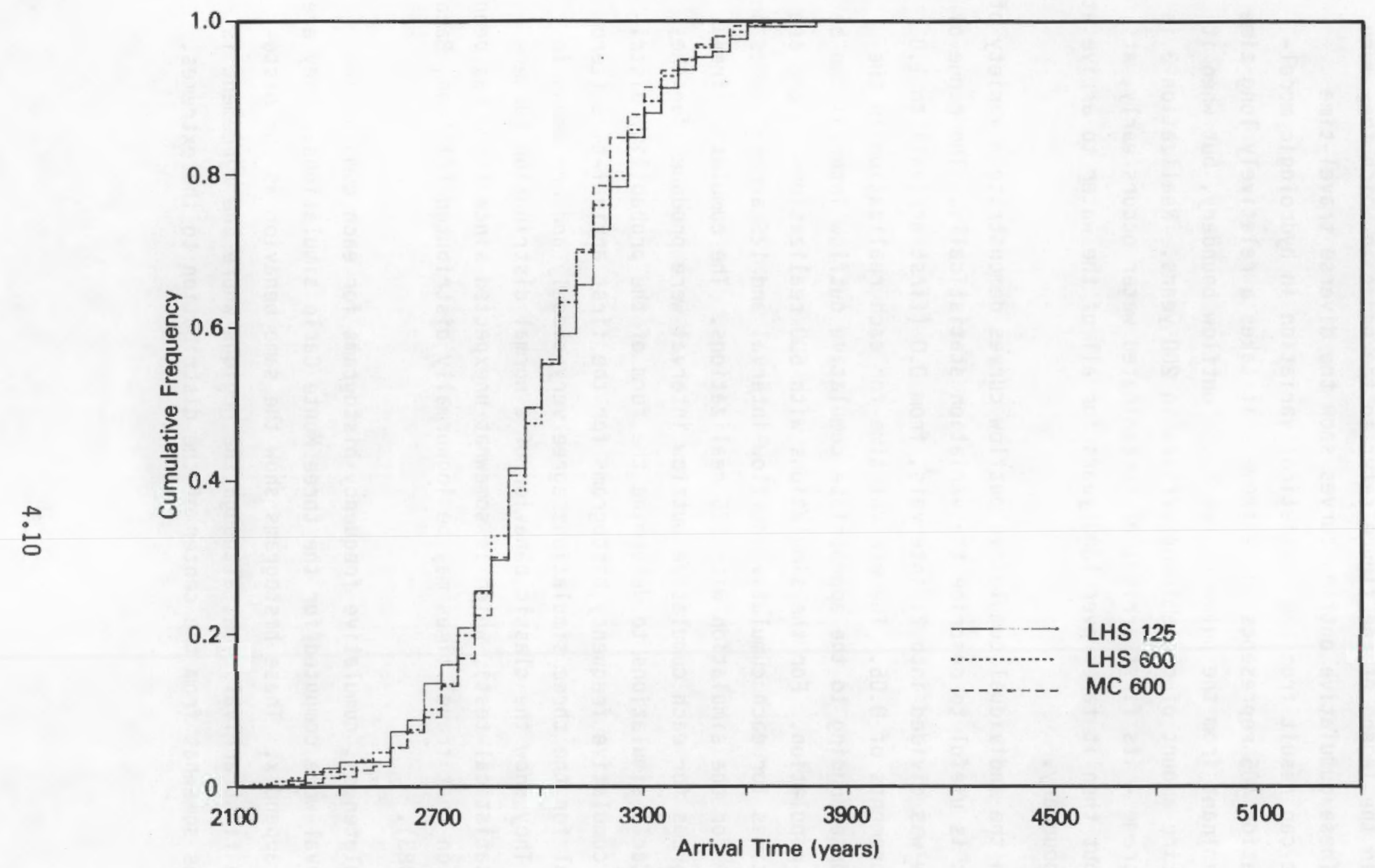

FIGURE 4.5. Cumulative Frequency Histograms of First Arrival Time 
Given the variability in the behavior of the individual outflow curves (see Figure 4.4), the idea of a single representative outflow curve is somewhat questionable (although the first-order technique estimates a mean travel time); however, it is still useful to compute an "average" outflow curve to locate the "population" of outflow curves. The average outflow curve was estimated by computing the mean arrival time for each of the 21 cumulative flux intervals. The average cumulative outflow curves for the three Monte Carlo simulations are shown in Figure 4.6. The curves agree quite closely, although there are some differences worthy of note. From the first arrival to about $20 \%$ of cumulative outflow, the three curves are nearly identical. For a cumulative outflow of more than $20 \%$, the mean of the unconstrained sampling simulation is slightly smaller than the means of the two Latin Hypercube simulations, which agree very closely. At about $80 \%$ of cumulative outflow, the mean of the 125-realization Latin Hypercube simulation begins to agree more closely with the unconstrained sampling curve.

The mean cumulative outflow curve estimated by the first-order method is indicated by FST ORD in Figure 4.6 and is quite similar in behavior to realization 406 in Figure 4.4. It discharges all contamination within 300 years. The mean outflow curves produced by the simulation methods differ substantially from the first-order mean cumulative outflow curve. The first-order mean outflow curve is steeper and represents a more uniform velocity field. It is conservative as it tends to discharge contamination quickly, but it is not conservative in its estimates of first arrival of the contaminant at the boundary.

One criteria used to determine suitability of a geologic medium as a potential high-level waste repository is that travel times to the accessible environment must be longer than a specified time. The "average" cumulative flux curve is not appropriate to address the issue of earliest possible arrival time. One needs a tolerance interval that contains a large percentage of the population of arrival times with nigh probability. In practice, the lower limit of the tolerance interval may be of more interest. 


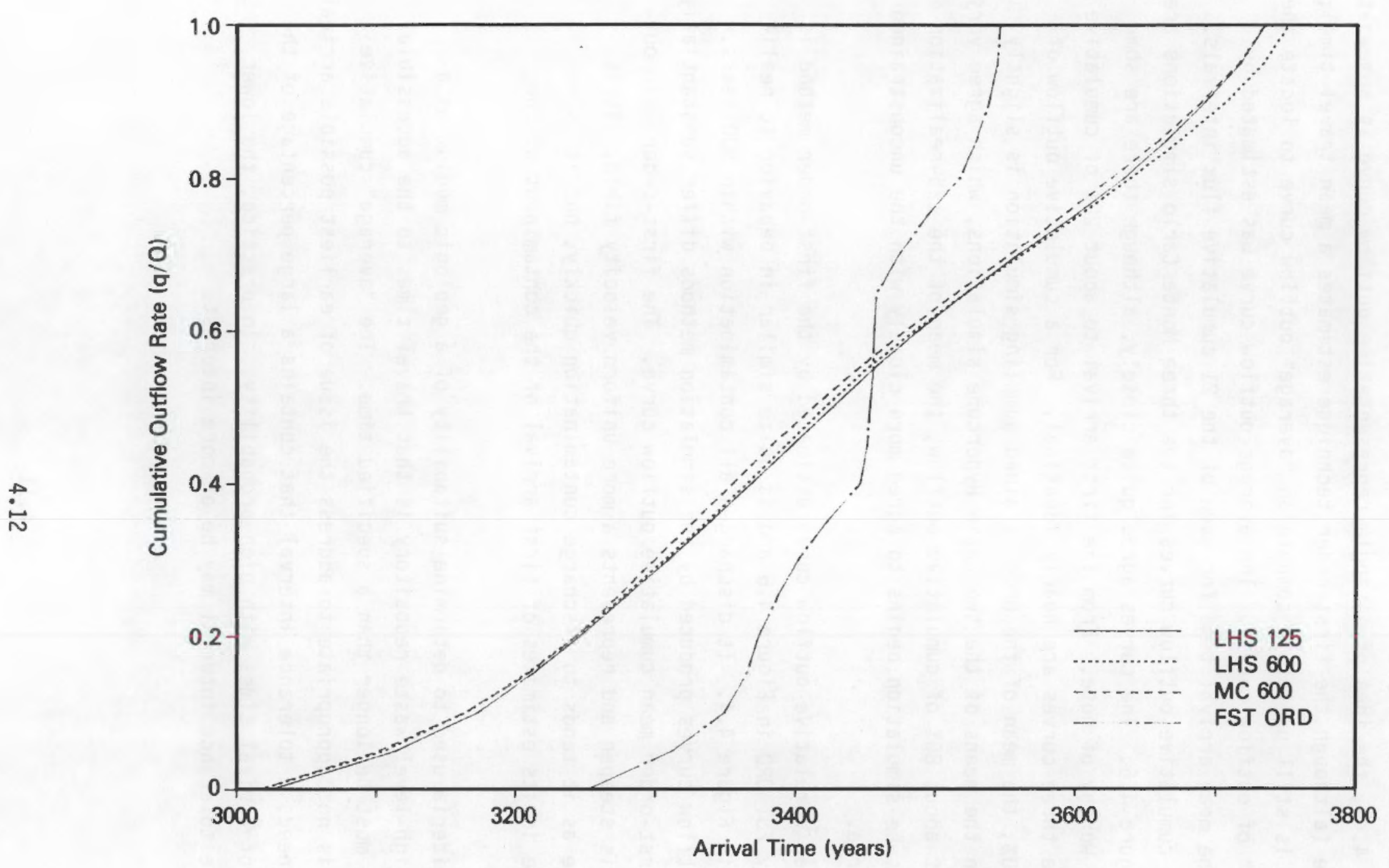

FIGURE 4.6. Mean Cumulative Outflow Curves 
An approximate 95\% tolerance interval (with 95\% probability) can be estimated for the cumulative outflow curves by computing the tolerance interval for each cumulative outflow interval and then plotting them. The limits of a tolerance interval for a normal distribution are

$$
\overline{T r}-k_{\alpha} s, \bar{T} r+k_{\alpha} s
$$

where $\bar{T} r$ is the estimated mean arrival time in each cumulative outflow interval (plotted in Figure 4.6), $s$ is the standard deviation of the arrival times in the interval, and $k_{\alpha}$ is a tolerance factor obtained from a table of normal tolerance factors (Natrella 1966).

Standard deviations were computed for each cumulative outflow interval in order to estimate a tolerance interval for the cumulative outflow curves. It was observed that the standard deviations of the Latin Hypercube simulations were consistently larger than those for the unconstrained sampling simulation for the first arrival to the $75 \%$ cumulative outflow intervals and then consistently smaller for the remaining outflow intervals. Except for the first arrival and $5 \%$ of the total outflow intervals, the standard deviations for the Monte Carlo simulations increased monotonically. However, the standard deviations estimated by the first-order method varied more in magnitude than those calculated from the simulations, and they did not increase monotonically.

The curves representing the lower limit of the approximate $95 \%$ tolerance interval for the three simulations are shown in Figure 4.7. They are close, but show more variability than the mean curves. The curve for the 125realization Latin Hypercube simulation is lower than the other two because $K_{\alpha}$ is a decreasing function of $N$. The slight differences in the standard deviations of the two 600-realization simulations is reflected in the relative positions of the tolerance curves. The lower tolerance limit for the first arrival, produced by the first-order method (also shown in Figure 4.7), is more variable than the ones produced by the simulation methods, thus reflecting the variability in the standard deviations. In fact, the cumulative frequency histograms of first arrival times from the simulations in Figure 4.5 show that approximately $10 \%$ (rather than the expected $2.5 \%$ seen for the simulation 


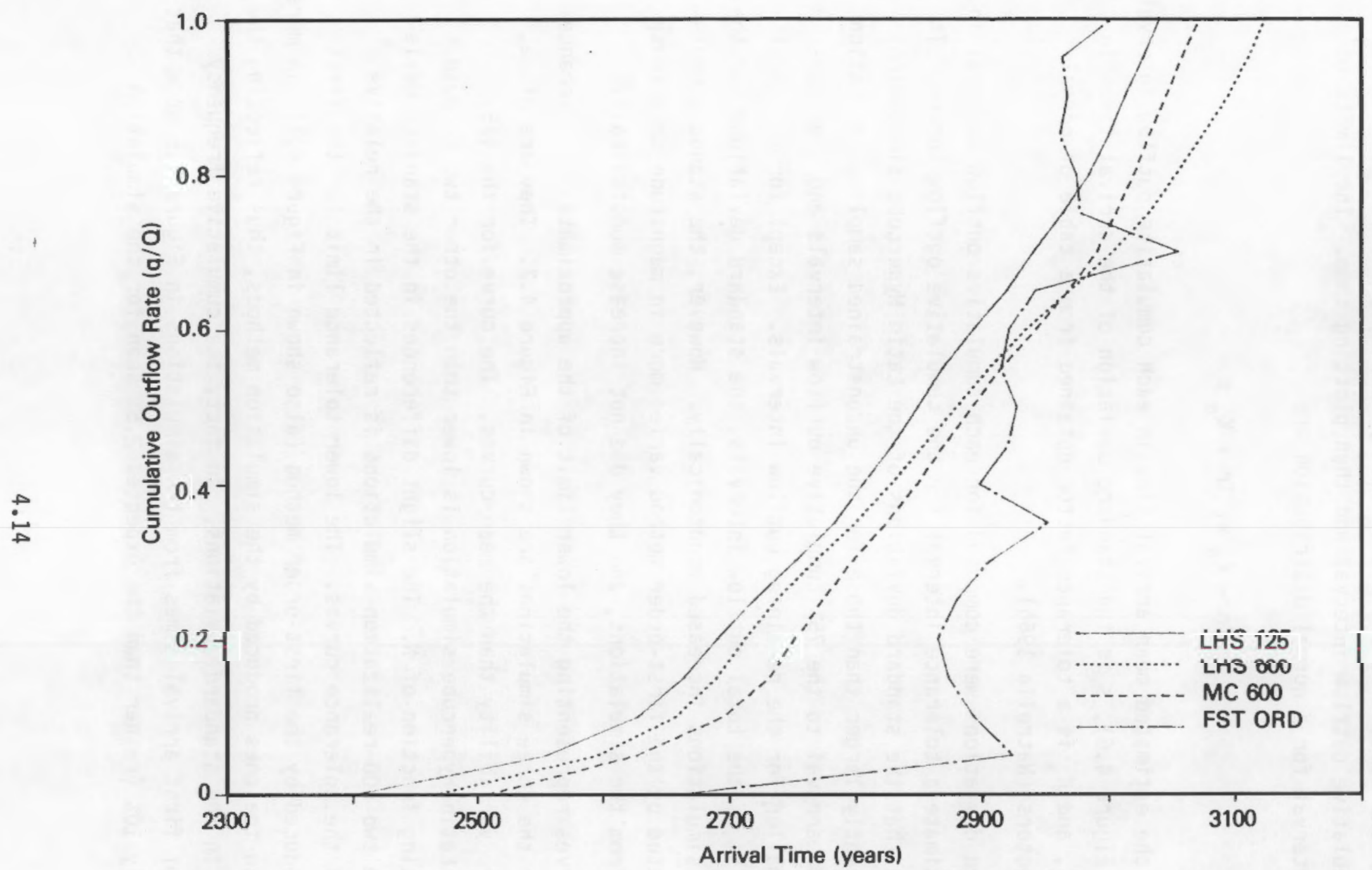

FIGURE 4.7. Lower Limit of Approximate 95\% Tolerance Interval for Cumulative Outflow Curves 
methods) are outside the tolerance range for the first-order method, suggesting that the tolerance range is too narrow to include the important early arrival times.

Comparing the uncertainty analysis results from the three Monte Carlo simulations and the first-order method shows that the simulation results are quite consistent, but there are substantial differences between the simulations and the first-order method. A 95\% lower tolerance interval limit of the cumulative outflow curve produced by the first-order method fails to include the first arrival times of approximately $10 \%$ of the realizations produced by the simulations, suggesting, in this particular application, that the tolerance interval limit would lead to unrealistically large estimates of first arrival times. 



\section{REFERENCES}

Clifton, P. M. 1981. Statistical Inverse Modeling and Geostatistical Analysis of the Avra Valley Aquifer. Thesis for Master of Science, University of Arizona, Tucson, Arizona.

Clifton, P. M., R. G. Baca and R. C. Arnett. 1983. Stochastic Analys is of Groundwater Traveltime for Long-Term Repository Performance Assessment. RHO-BW-SA-323P, Rockwell Hanford Operations, Richland, Washington.

Clifton, P. M., and S. P. Neuman. 1982. "Effects of Kriging and Inverse Modeling on Conditional Simulation of the Avra Valley Aquifer in Southern Arizona." Water Resources Research 18(4):1215-1234.

Cochran, W. G. 1963. Sampling Statistics. 2nd ed. John Wiley and Sons, New York.

Harper, W. V., and S. K. Gupta. 1983. Sensitivity/Uncertainty Analysis of a Borehole Scenario Comparing Latin Hypercube Sampling and Deterministic Sensitivity Approaches. BMI/0NWI-516, Office of Nuclear Waste Isolation, Battelle Memorial Institute, Columbus, Ohio.

Iman, R. L., and W. J. Conover. 1982. "A Distribution-Free Approach to Inducing Rank Correlation Among Input Variables." Communications in Statistics B11(3):311-334.

Iman R. L., and M. J. Shortencarier. 1984. A Fortran 77 Program and User's Guide for the Calculation of Partial Regression Coefficients. NUREG/CR-4122, SAN083-2365, Sandia National Laboratories, Albuquerque, New Mexico.

Kempthorne, 0. 1952. Design and Analysis of Experiments. John Wiley and Sons, New York.

McKay, M. D., W. J. Conover and R. J. Beckman. 1979. "A Comparison of Three Methods for Selecting Values of Input Variables in the Analysis of Output from a Computer Code." Technometrics 21(2):239-245.

Natrella, M. G. 1966. Experimental Statistics. John Wiley and Sons, New York.

Nelson, R. W., E. A. Jacobson and W. Conbere. 1985. "An Approach to Uncertainty Assessment for Fluid Flow and Contaminant Transport Modeling in Heterogeneous Groundwater Systems." In Proceedings of Advances in Transport Phenomena in Porous Media, eds. J. Bear and M. Yavuz Corapcioglu, pp. 703726. Martinus Nijhoff Publishers, Dordrecht, Netherlands.

Neuman, S. P. 1980. "A Statistical Approach to the Inverse Problem of Aquifer Hydrology. Part 3. Improved Solution Method and Added Perspective." Water Resources Research 16(2):331-346. 
Sagar, B., and P. M. Clifton. 1985. Stochastic Groundwater Flow Modeling Using the Second-Order Method. RHO-BW-SA-364P, Rockwell Hanford Operations, Richland, Washington. 
APPENDIX

HISTOGRAMS FOR CUMULATIVE OUTFLOW INTERVALS FOR ALL THREE SIMULATIONS 


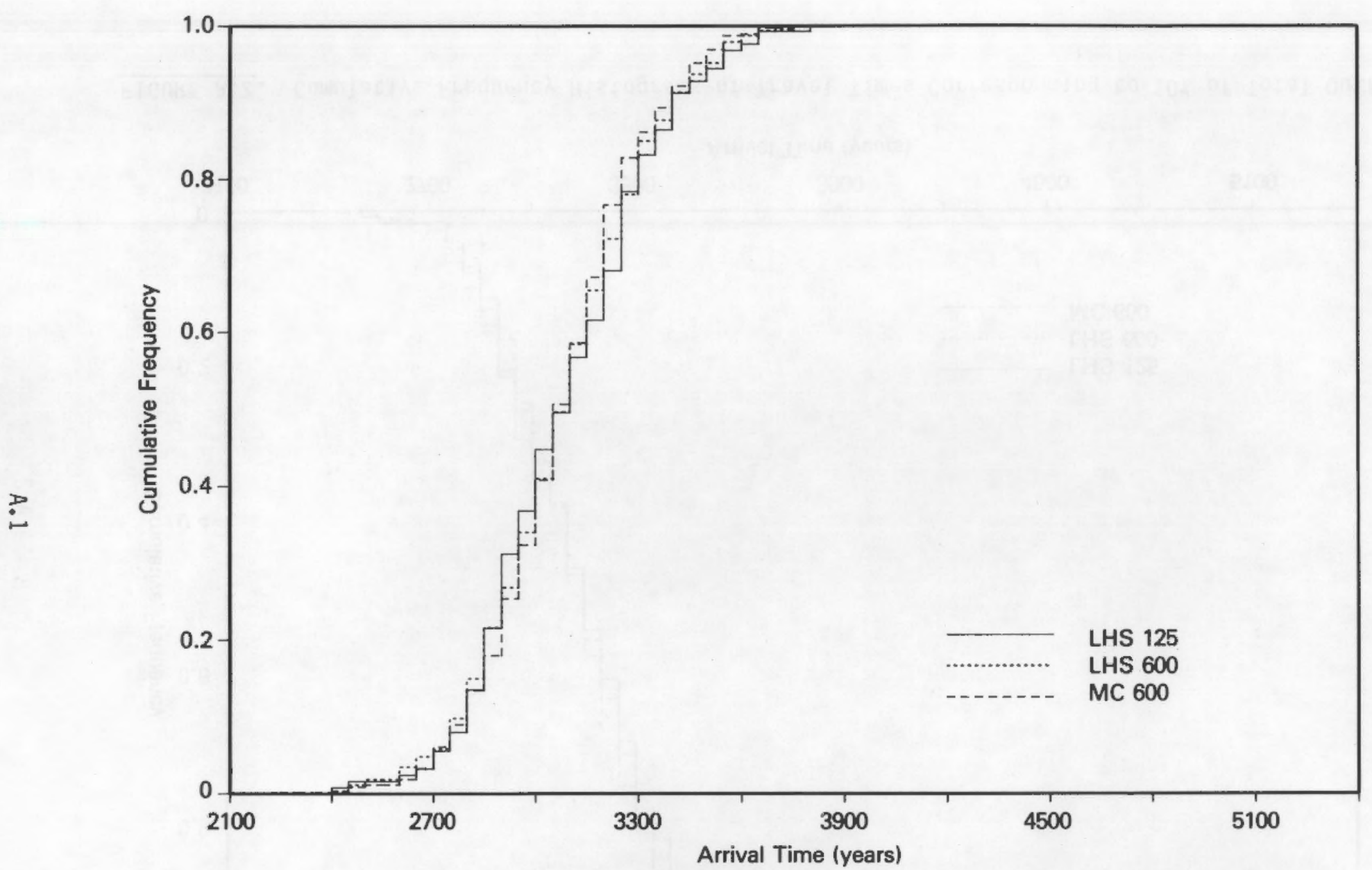

FIGURE A.1. Cumulative Frequency Histograms of Travel Times Corresponding to $5 \%$ of Total Outflow 


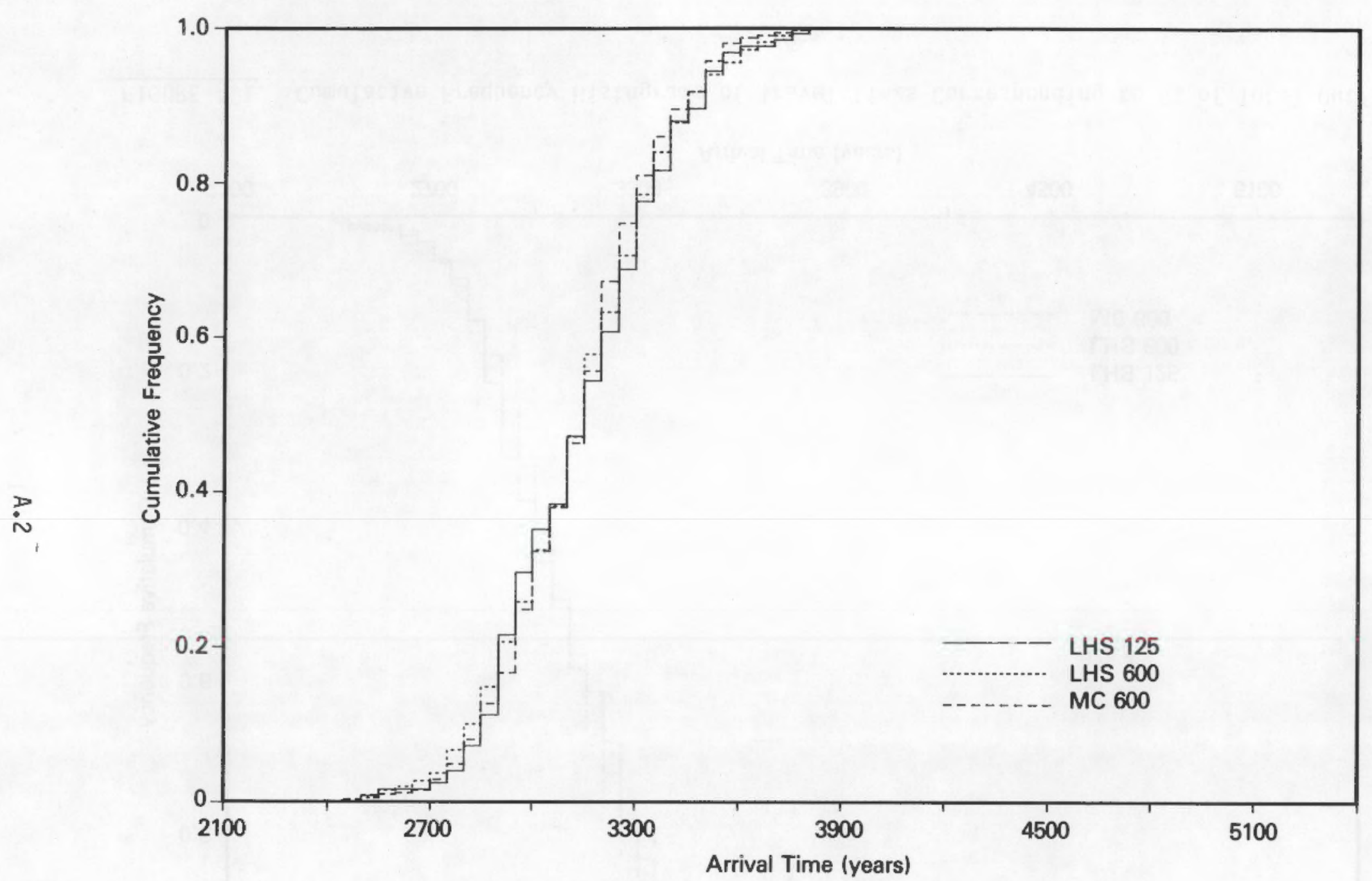

FIGURE A.2. Cumulative Frequency Histograms of Travel Times Corresponding to $10 \%$ of Total Outflow 


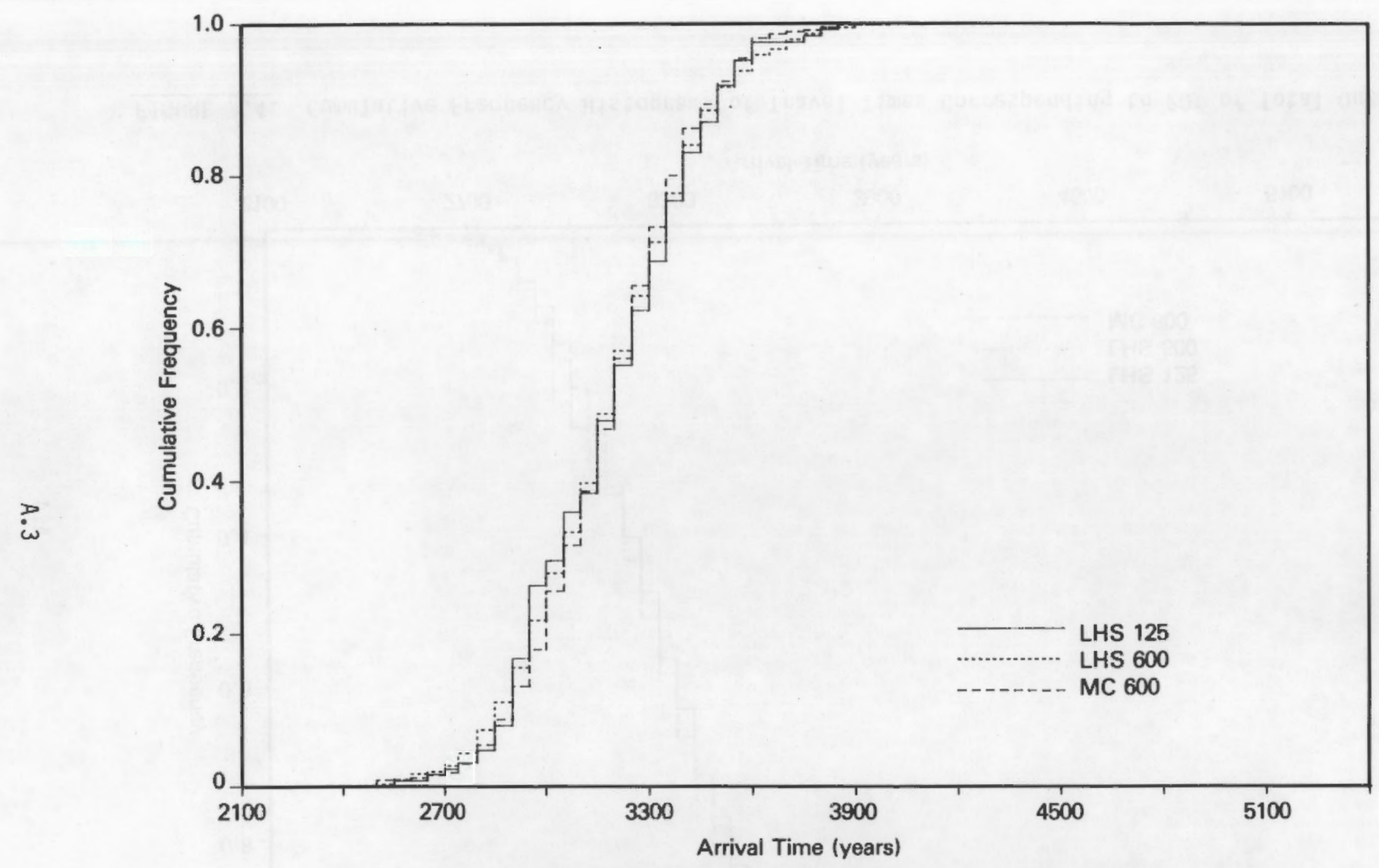

FIGURE A.3. Cumulative Frequency Histograms of Trave1 Times Corresponding to 15\% of Total Outflow 


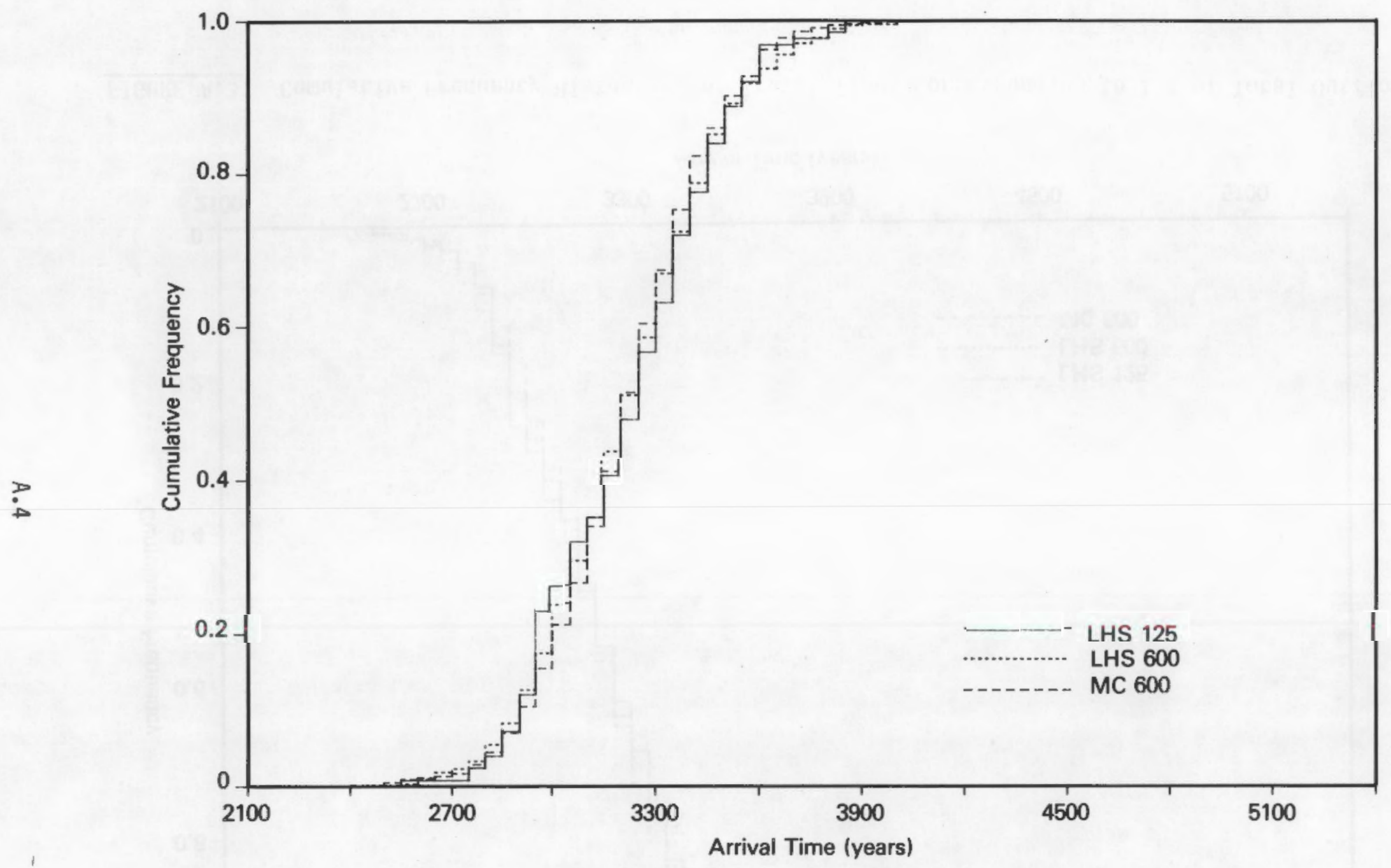

FIGURE A.4. Cumulative Frequency Histograms of Travel Times Corresponding to $20 \%$ of Total Outflow 


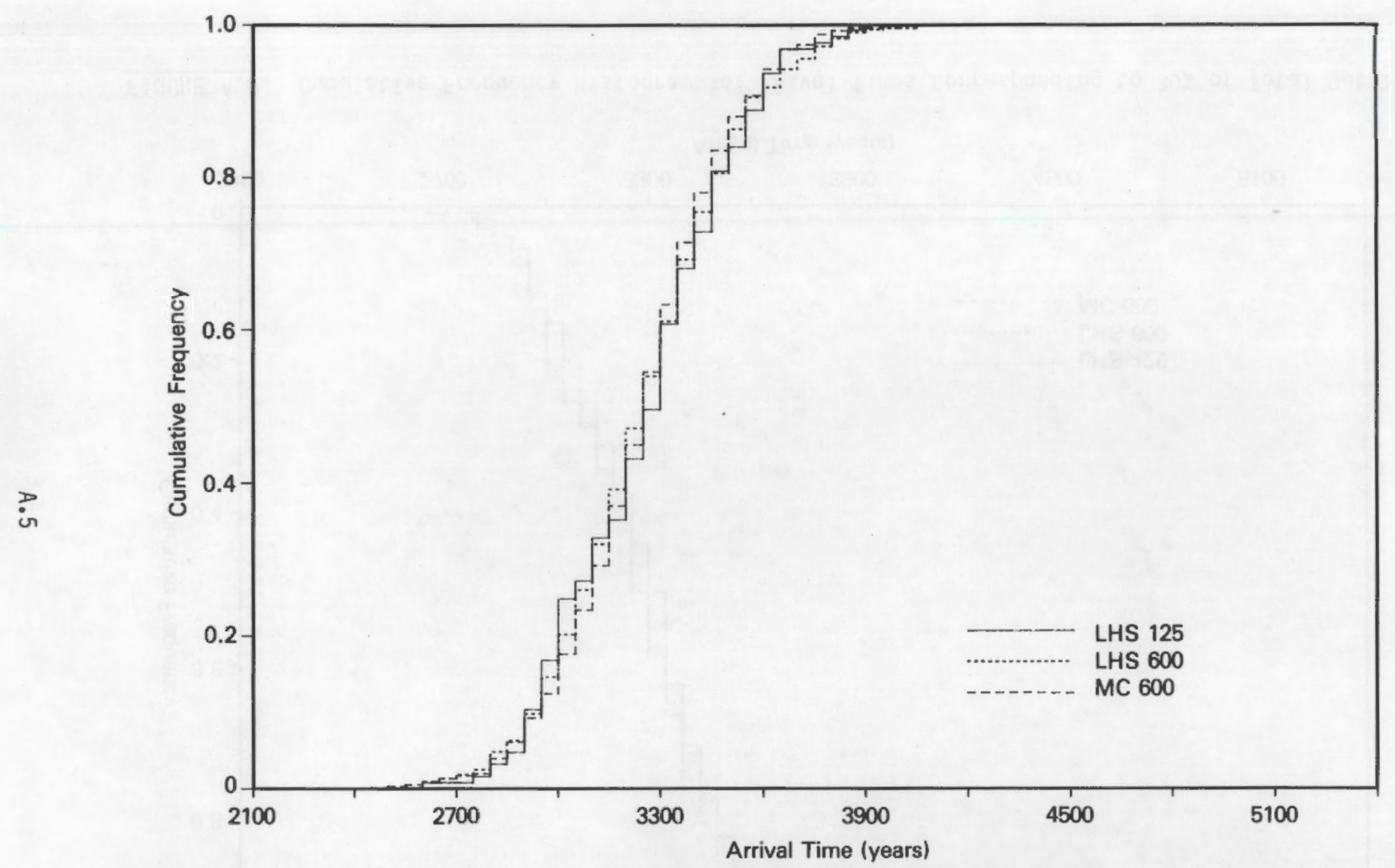

FIGURE A.5. Cumulative Frequency Histograms of Travel Times Corresponding to $25 \%$ of Total Outflow 


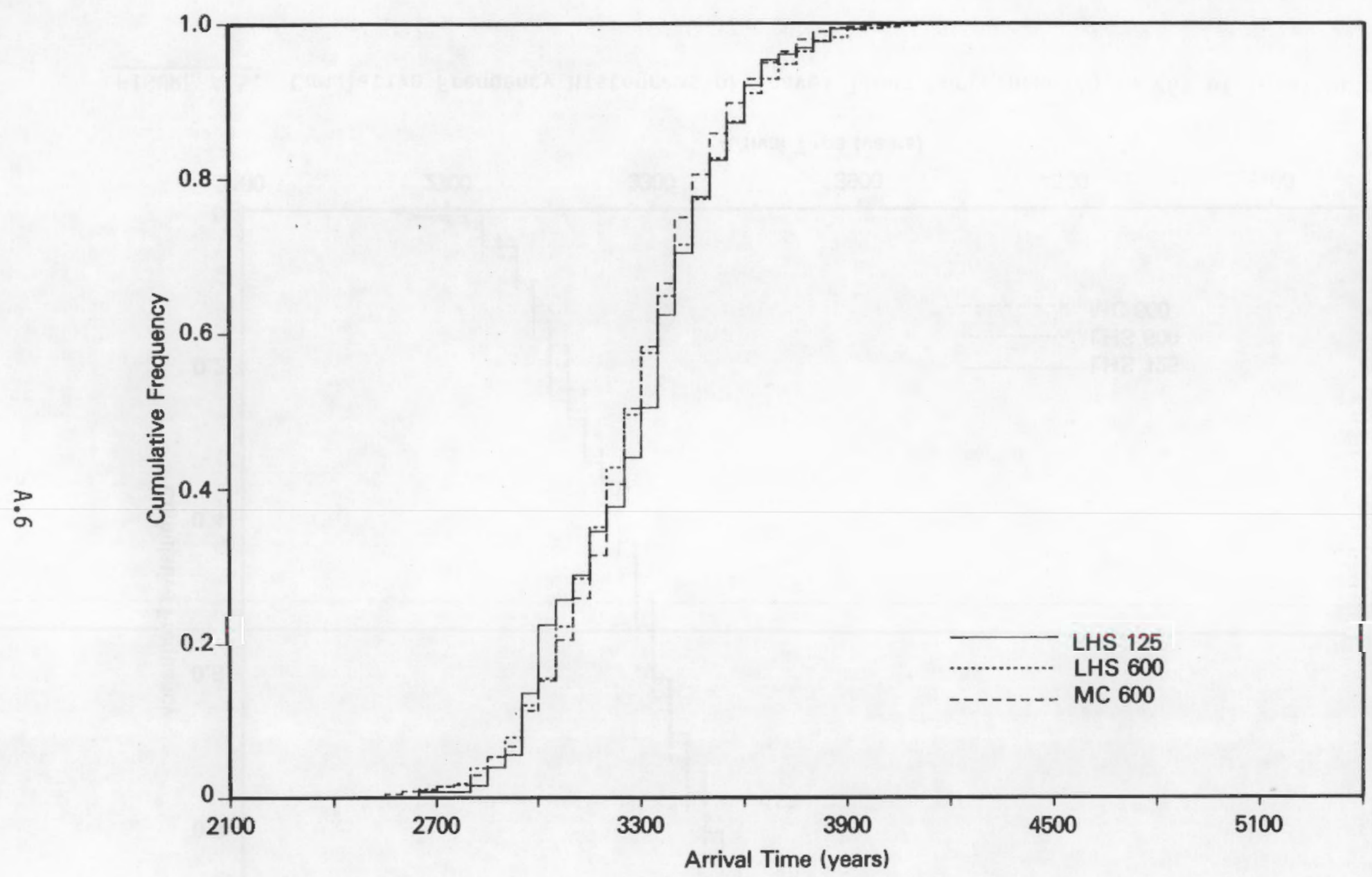

FIGURE A.6. Cumulative Frequency Histograms of Travel Times Corresponding to $30 \%$ of Total Outflow 


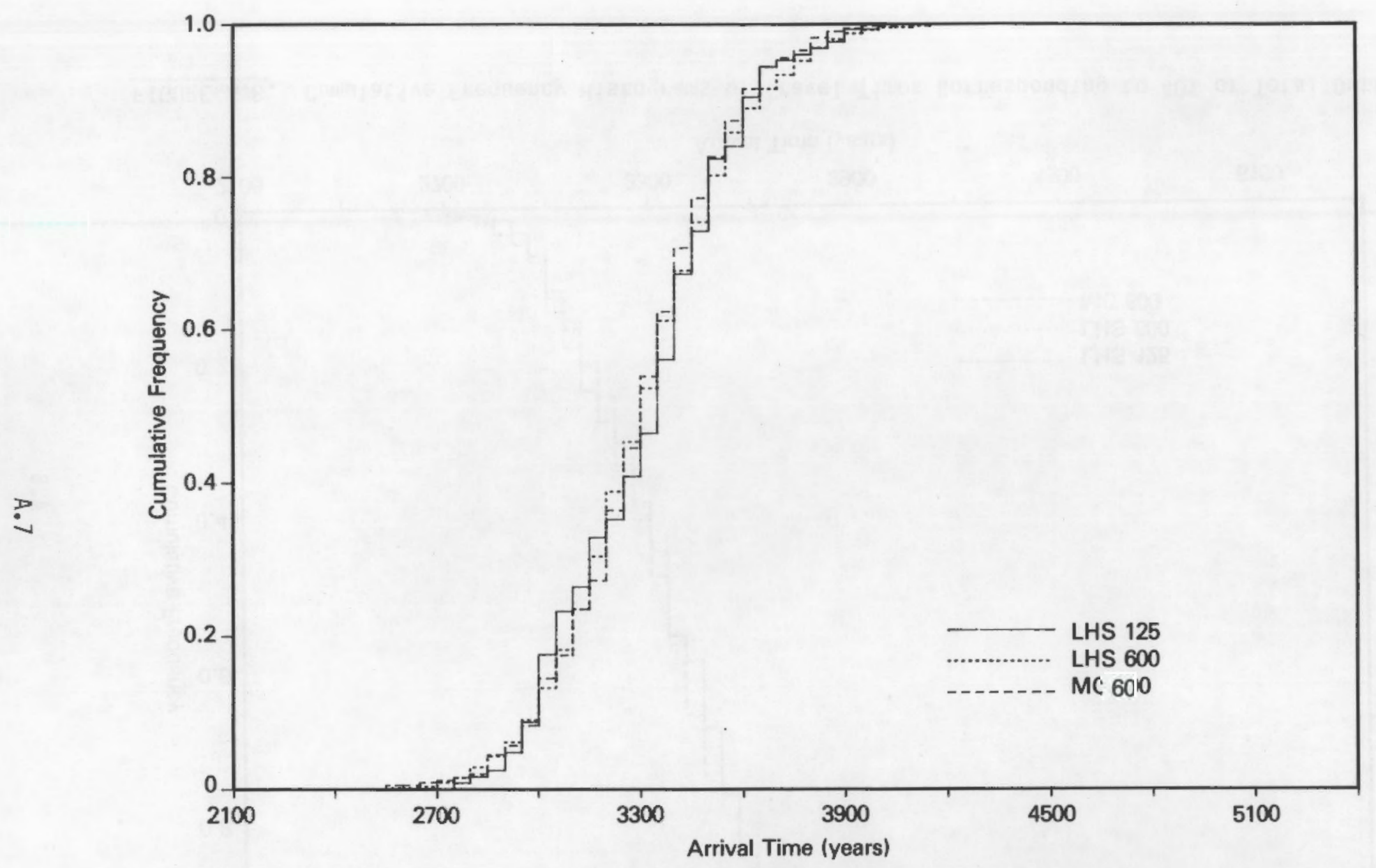

FIGURE A.7. Cumulative Frequency Histograms of Travel Times Corresponding to $35 \%$ of Total Outflow 


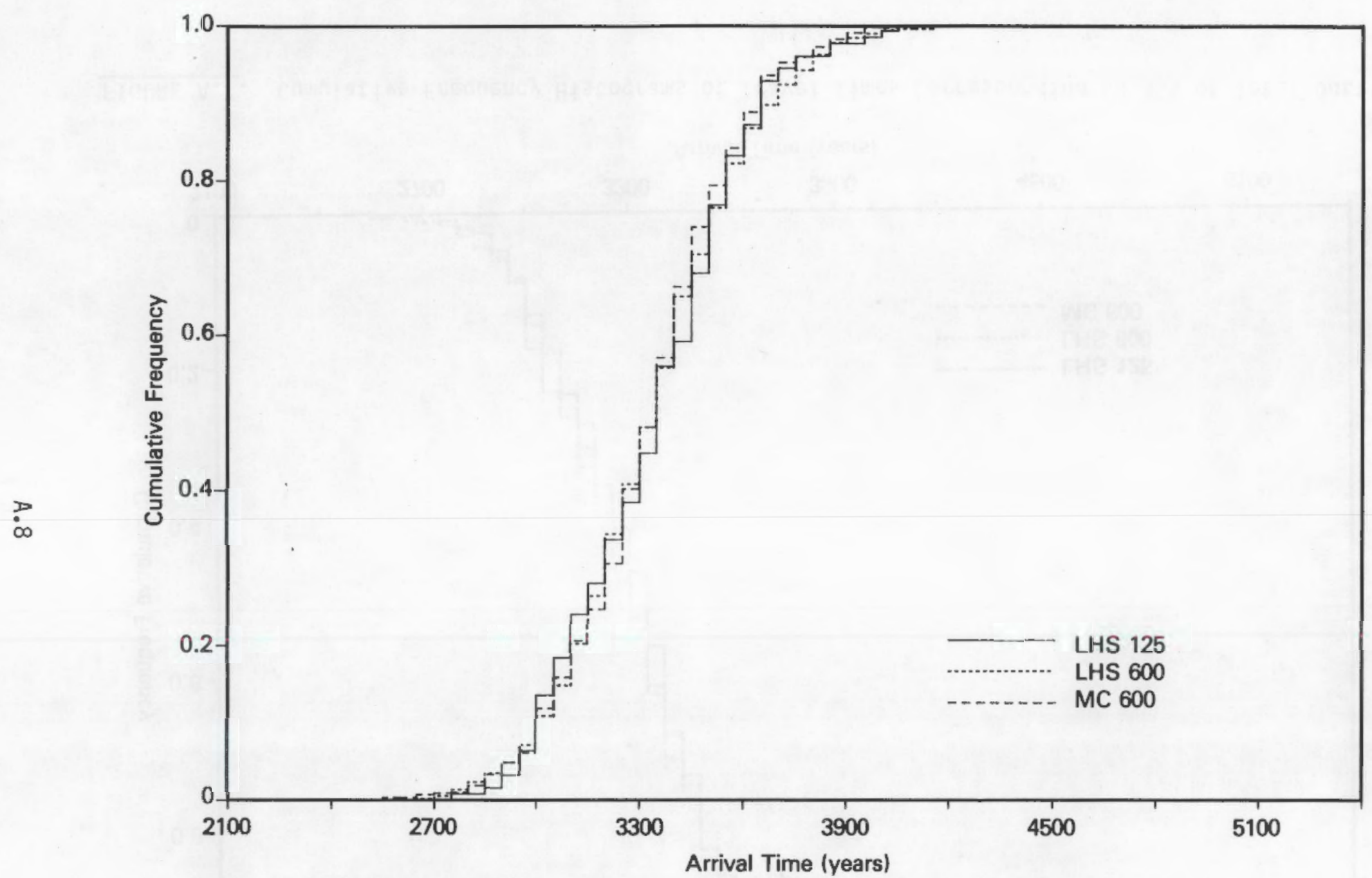

FIGURE A.8. Cumulative Frequency Histograms of Travel Times Corresponding to $40 \%$ of Total Outflow 


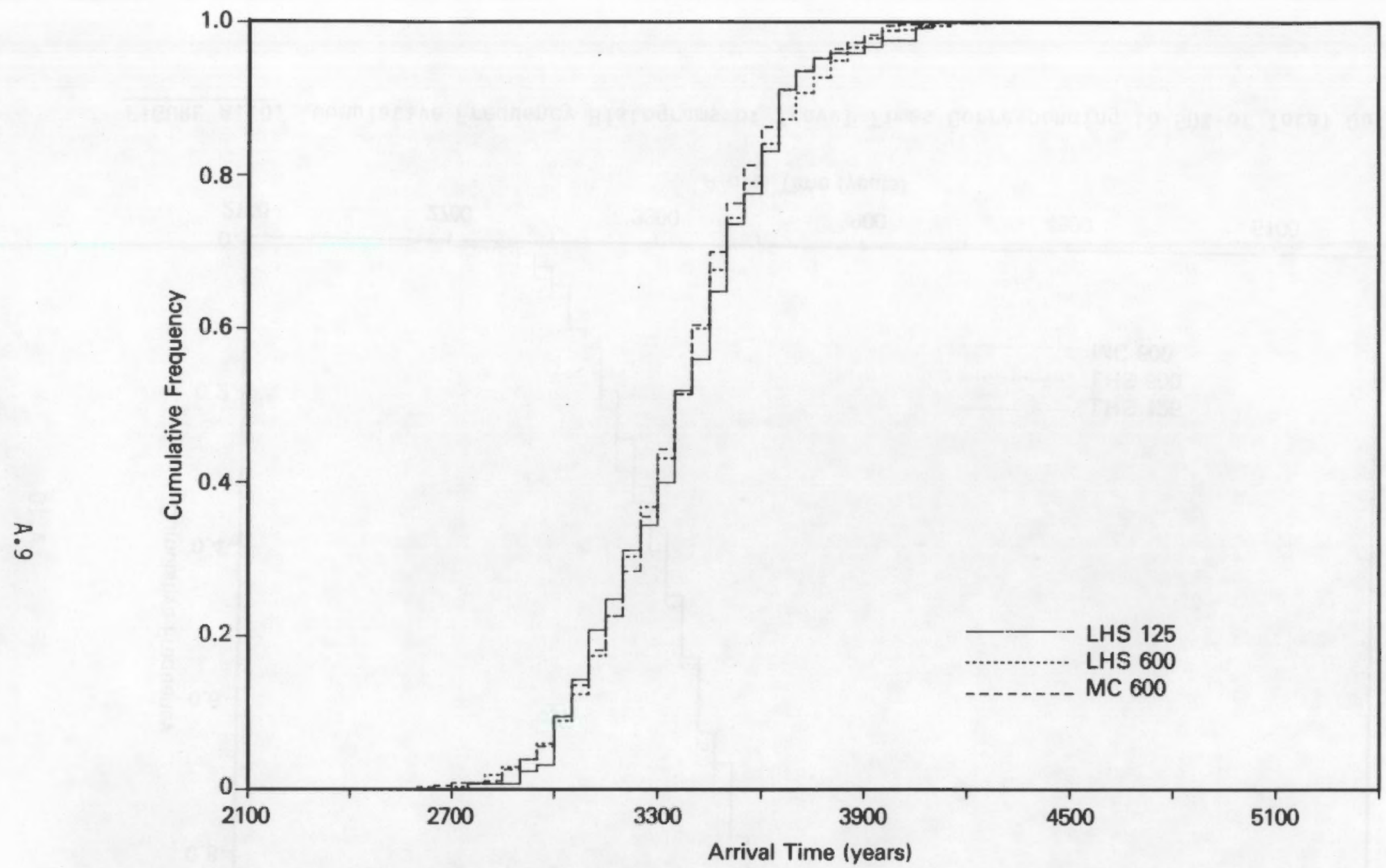

FIGURE A.9. Cumulative Frequency Histograms of Travel Times Corresponding to $45 \%$ of Total 0utflow 


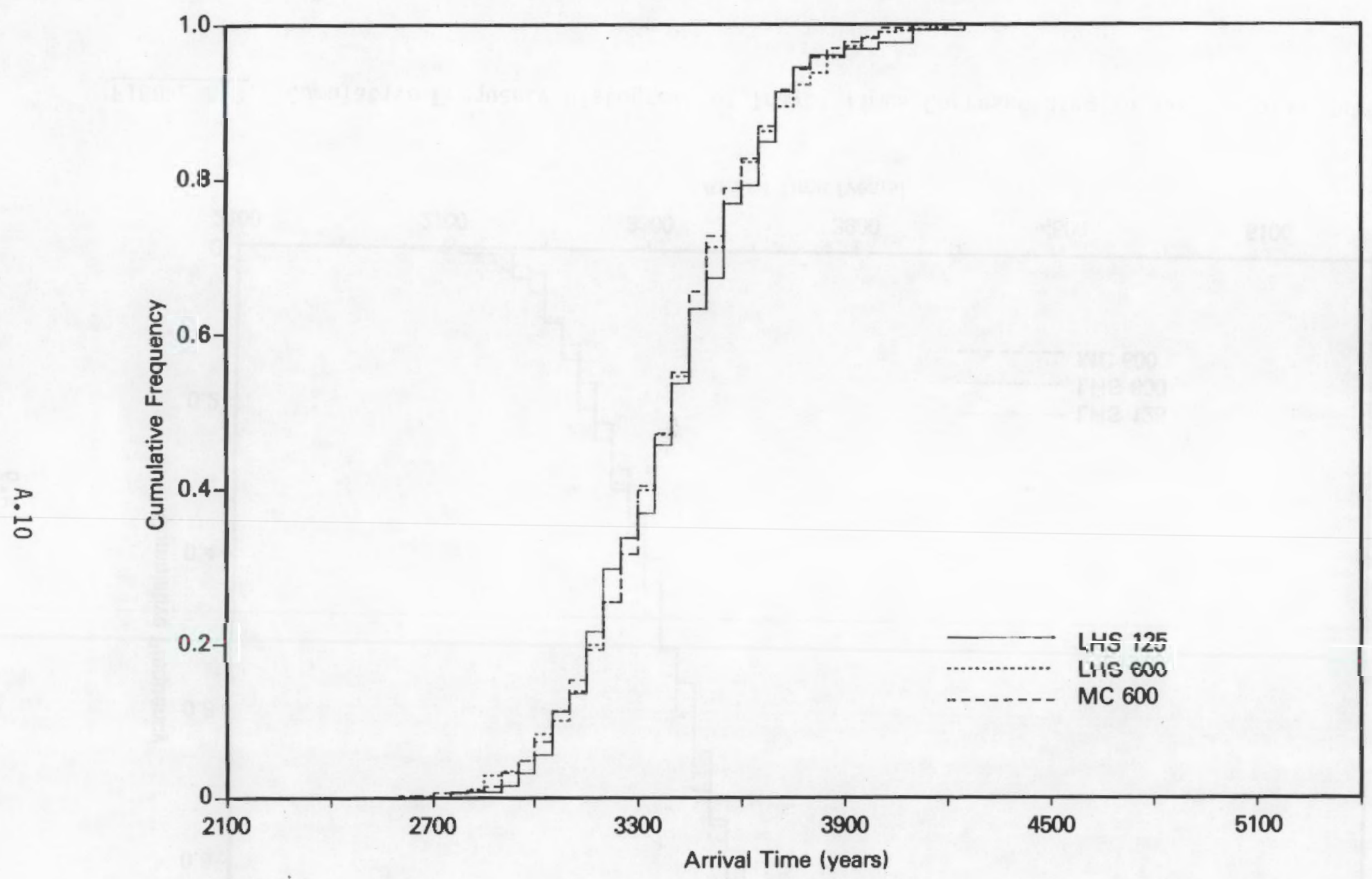

FIGURE A.10. Cumulative Frequency Histograms of Travel Times Corresponding to $50 \%$ of Total Outflow 


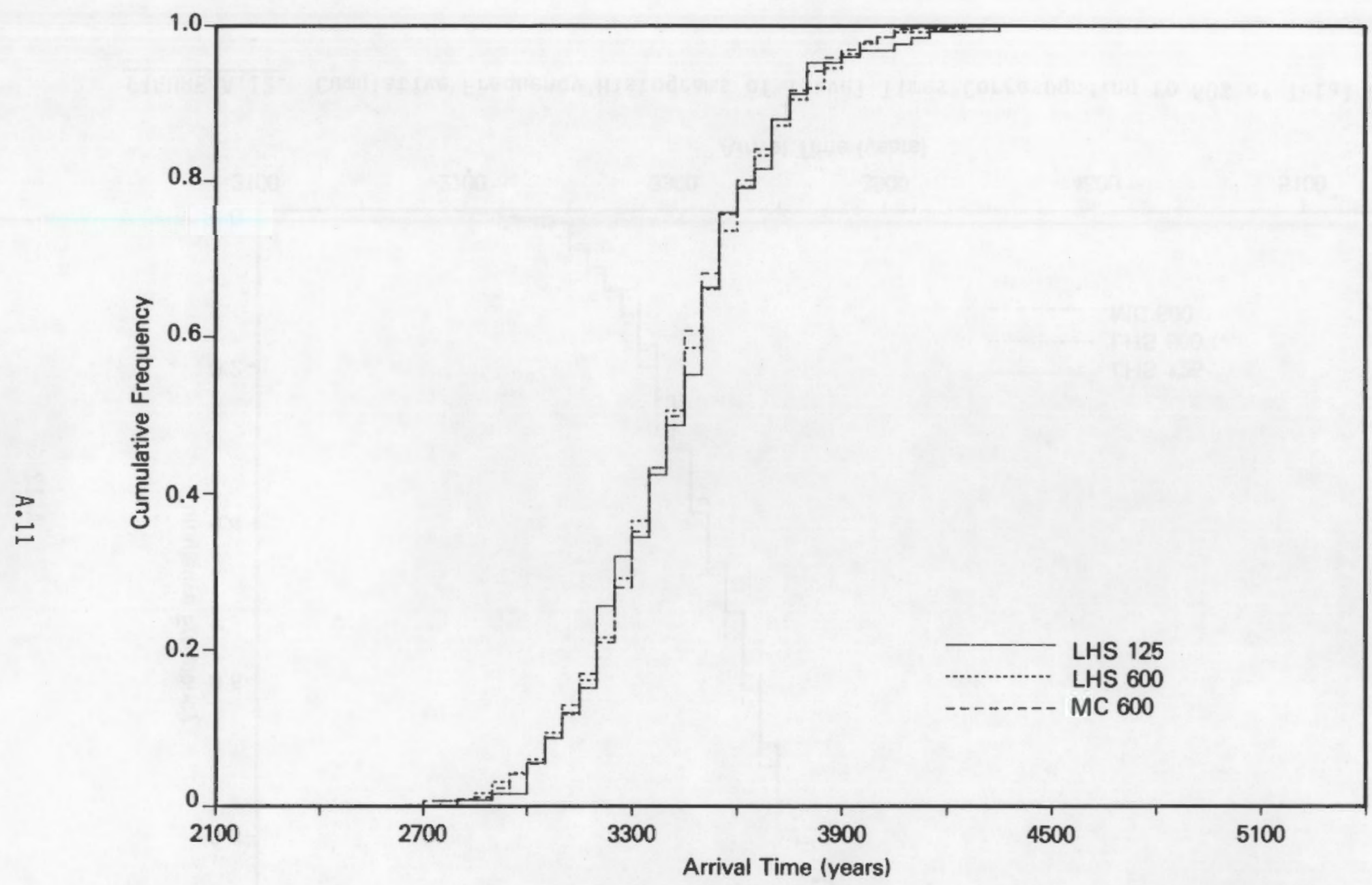

FIGURE A.11. Cumulative Frequency Histograms of Travel Times Corresponding to 55\% of Total 0utflow 


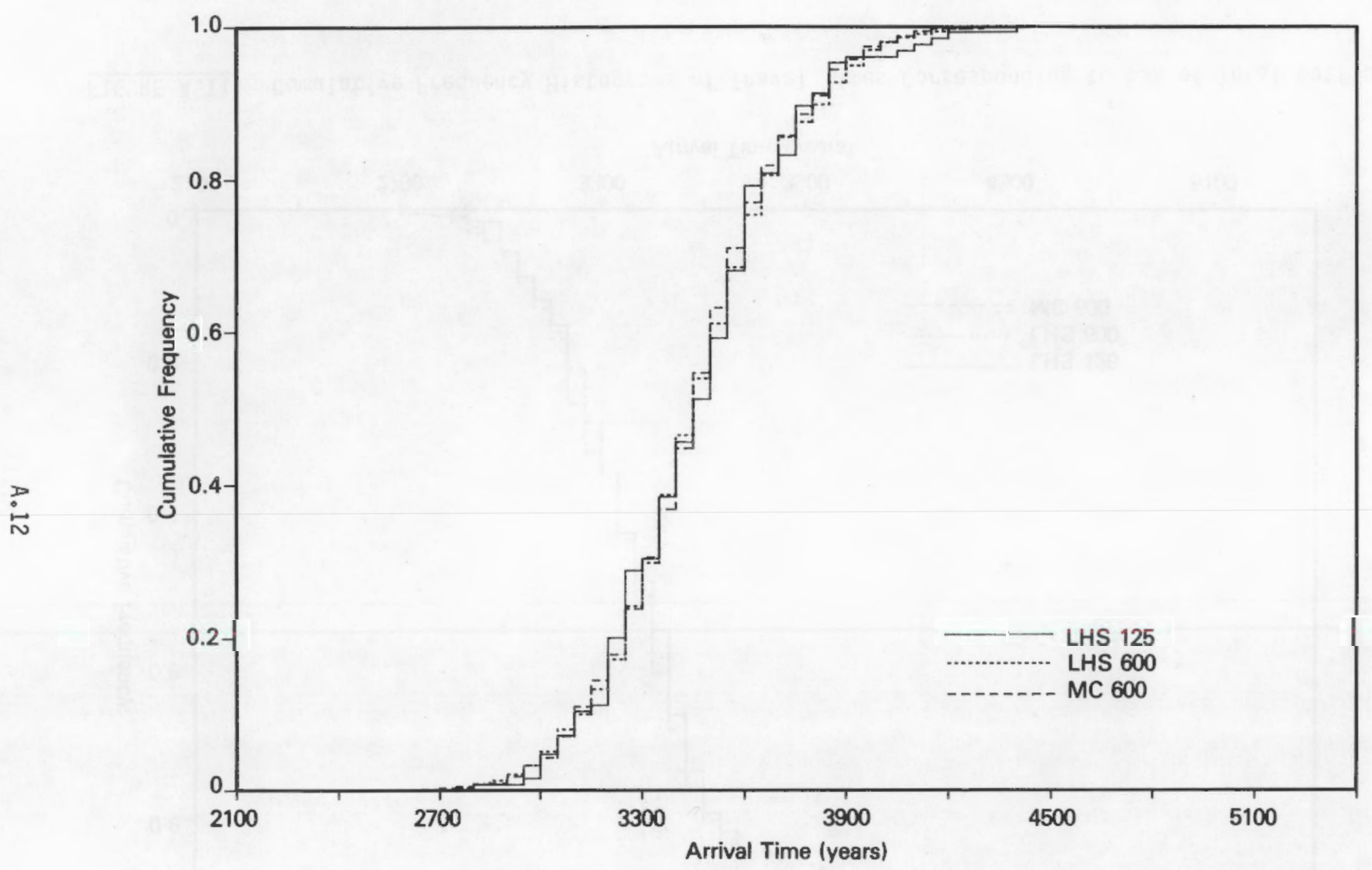

FIGURE A.12. Cumulative Frequency Histograms of Travel Times Corresponding to $60 \%$ of Total Outflow 


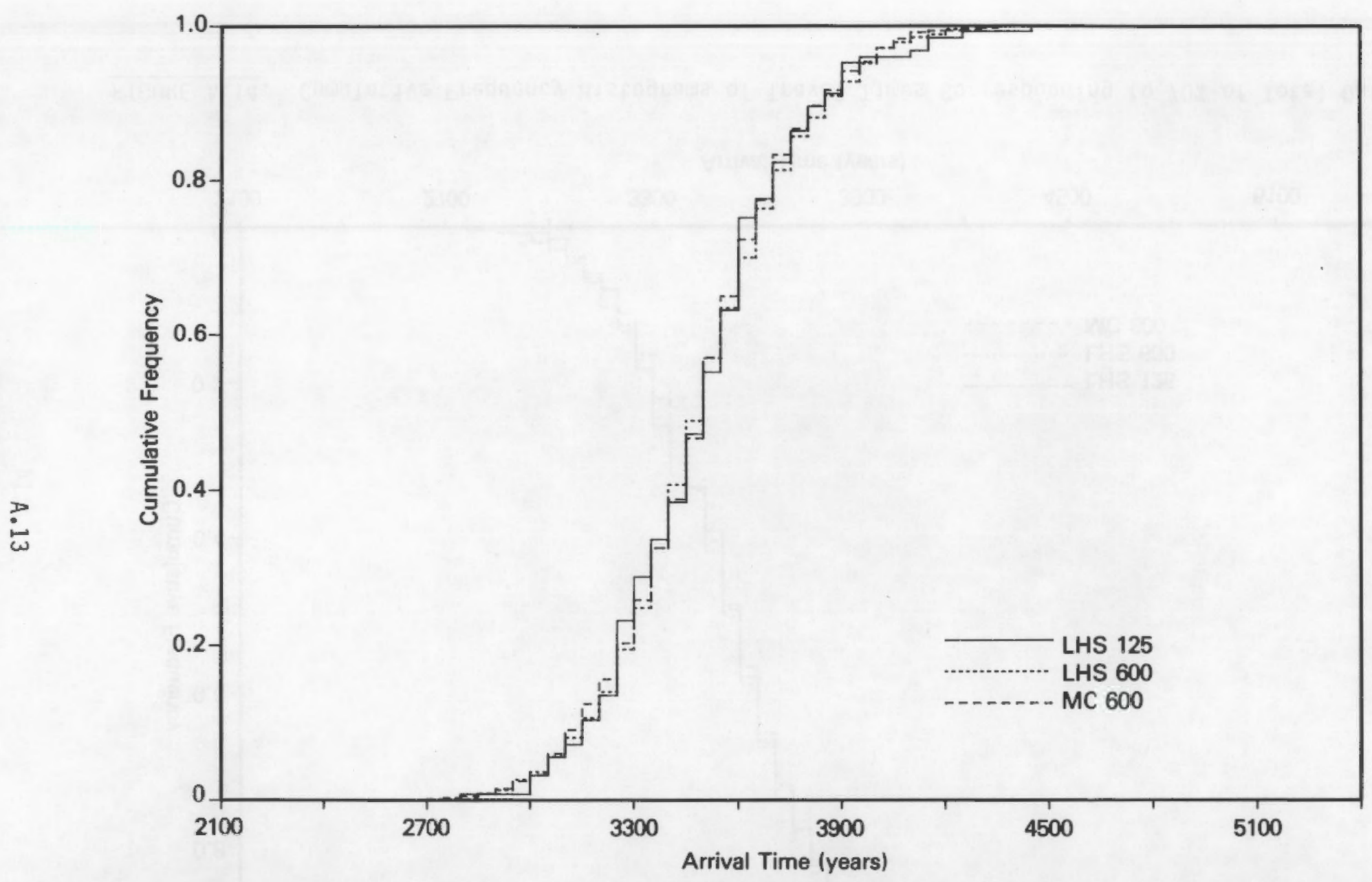

FIGURE A.13. Cumulative Frequency Histograms of Travel Times Corresponding to $65 \%$ of Total 0utflow 


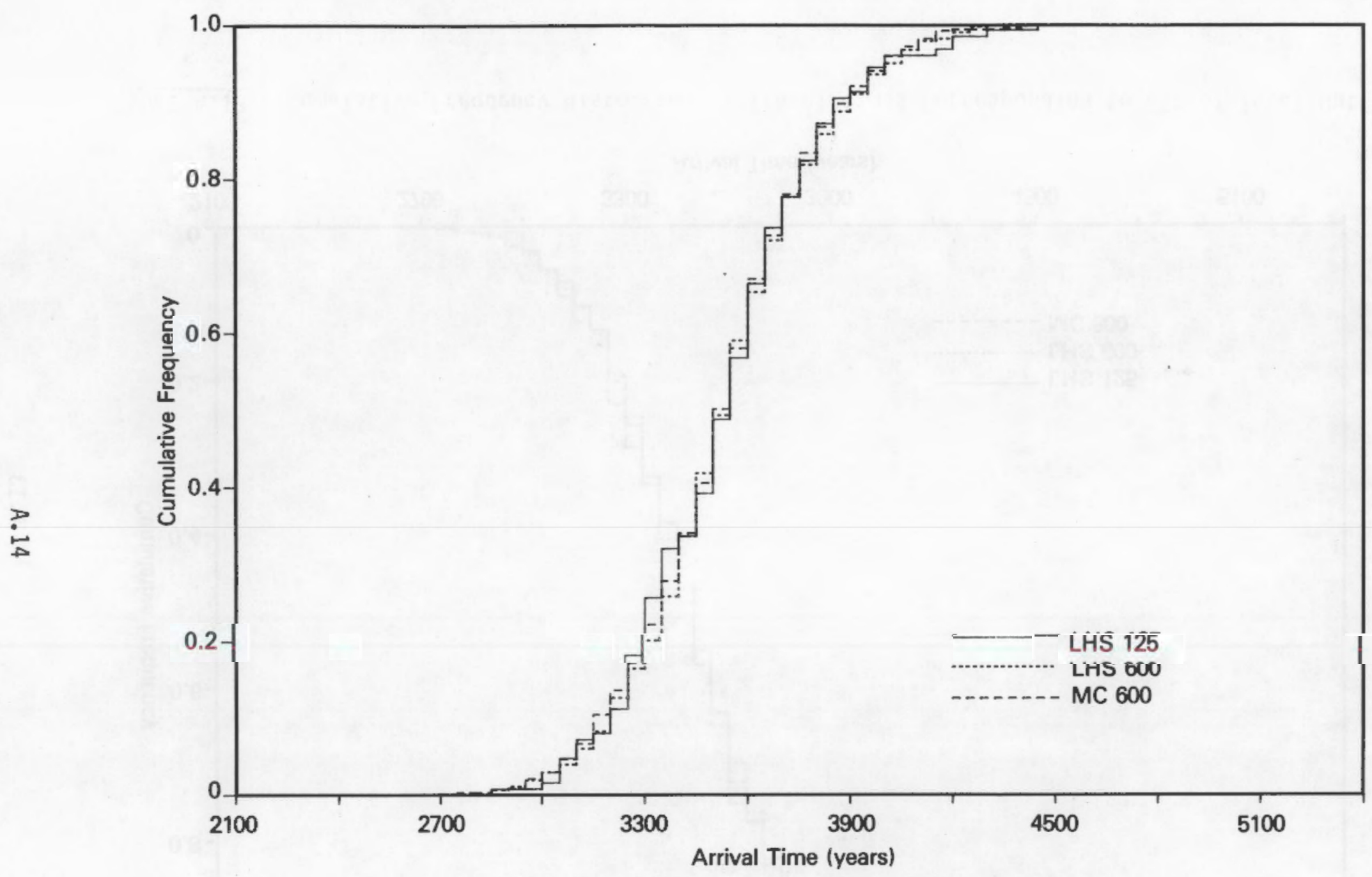

FIGURE A.14. Cumulative Frequency Histograms of Travel Times Corresponding to $70 \%$ of Total Outflow 


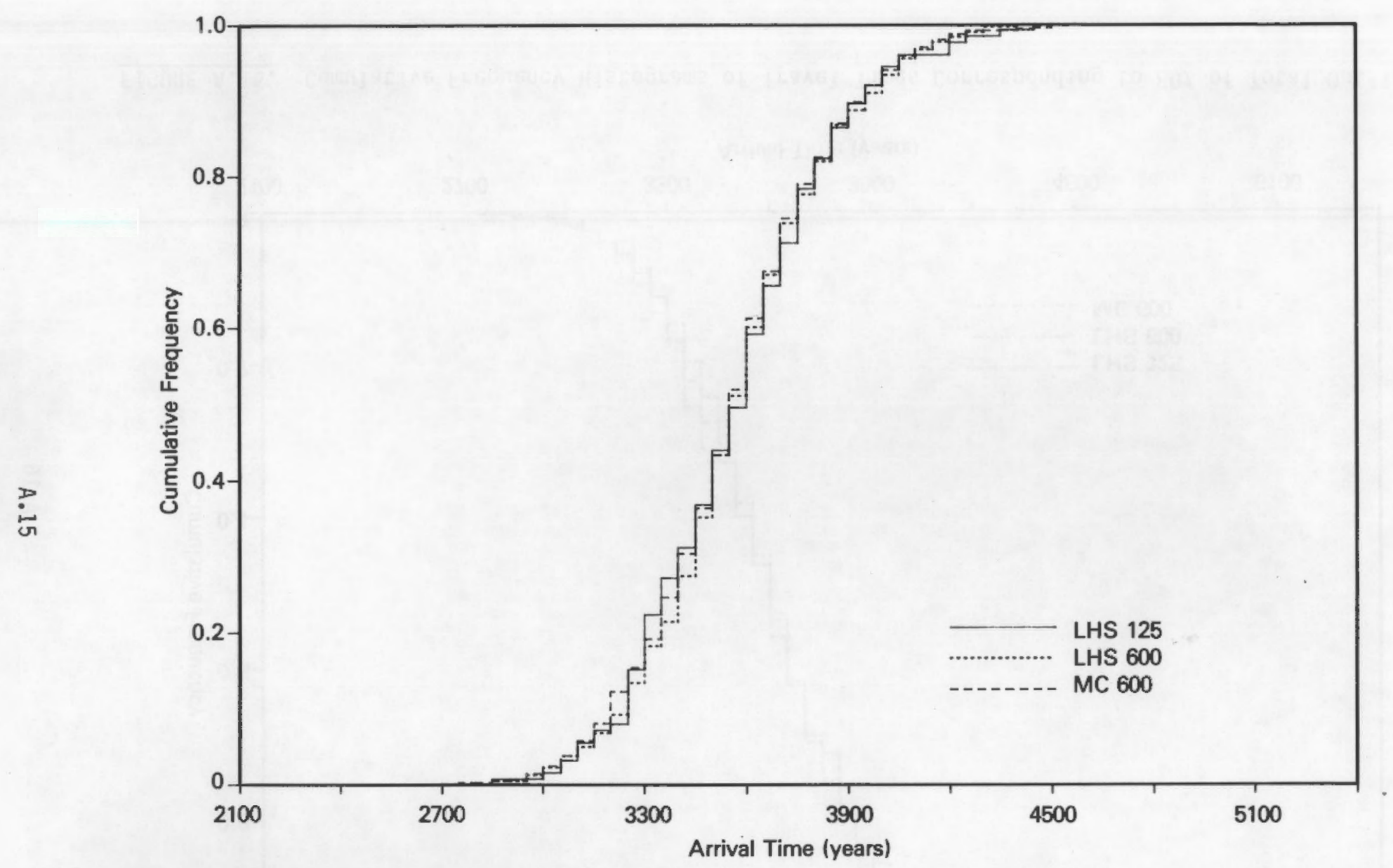

FIGURE A.15. Cumulative Frequency Histograms of Travel Times Corresponding to $75 \%$ of Total Outflow 


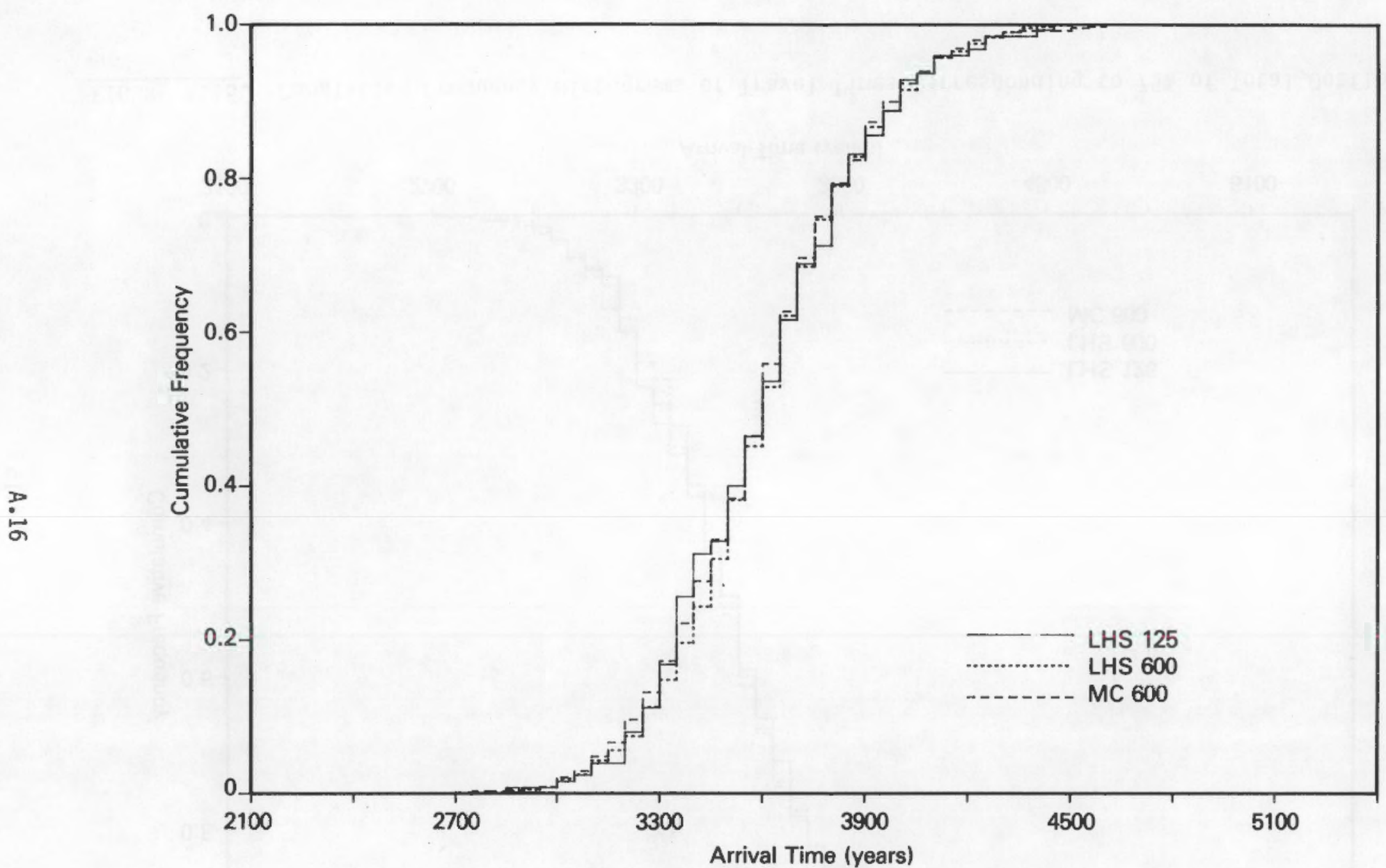

FIGURE A.16. Cumulative Frequency Histograms of Travel Times Corresponding to $80 \%$ of Total Outflow 


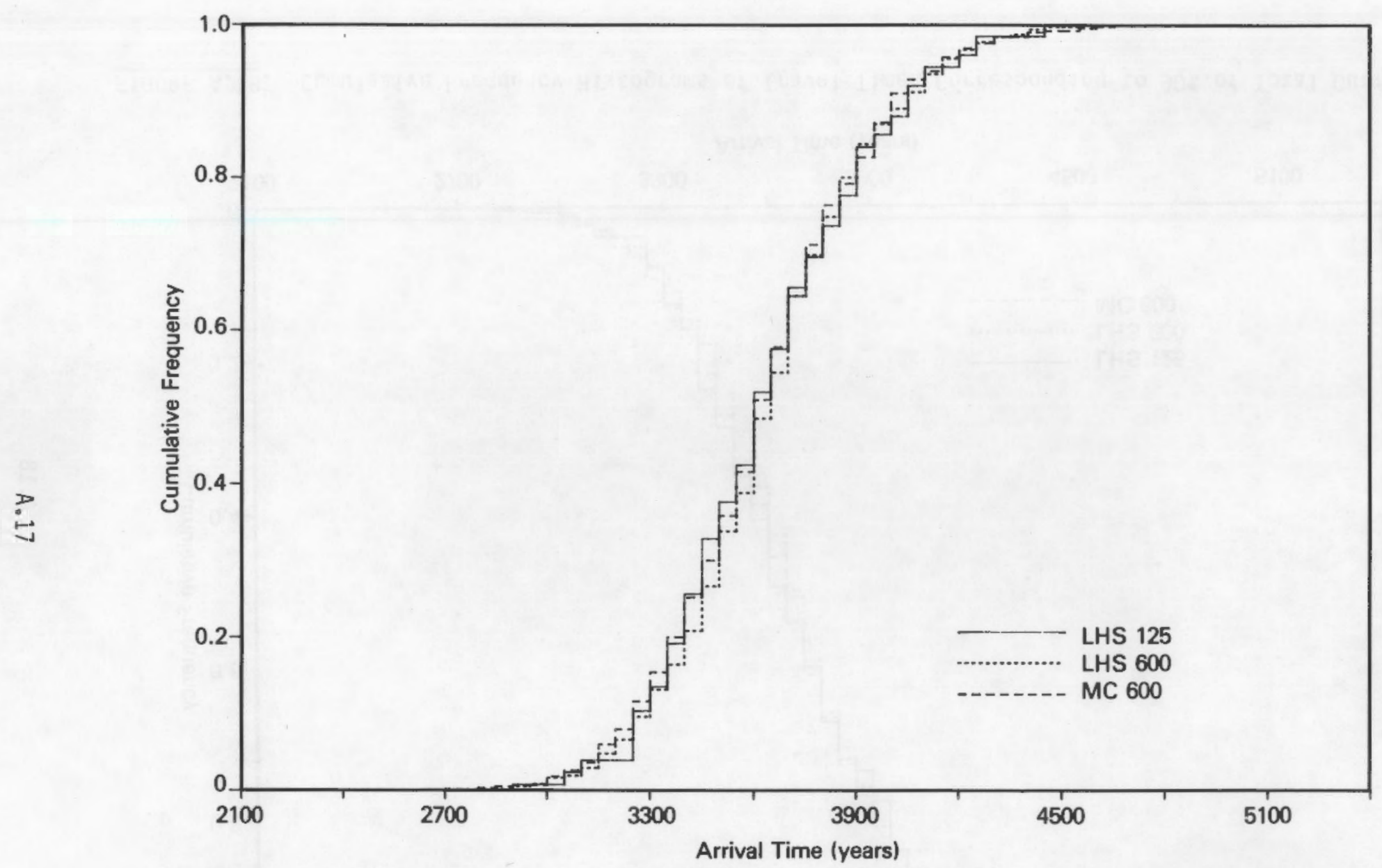

FIGURE A.17. Cumulative Frequency Histograms of Travel Times Corresponding to $85 \%$ of Total Outflow 


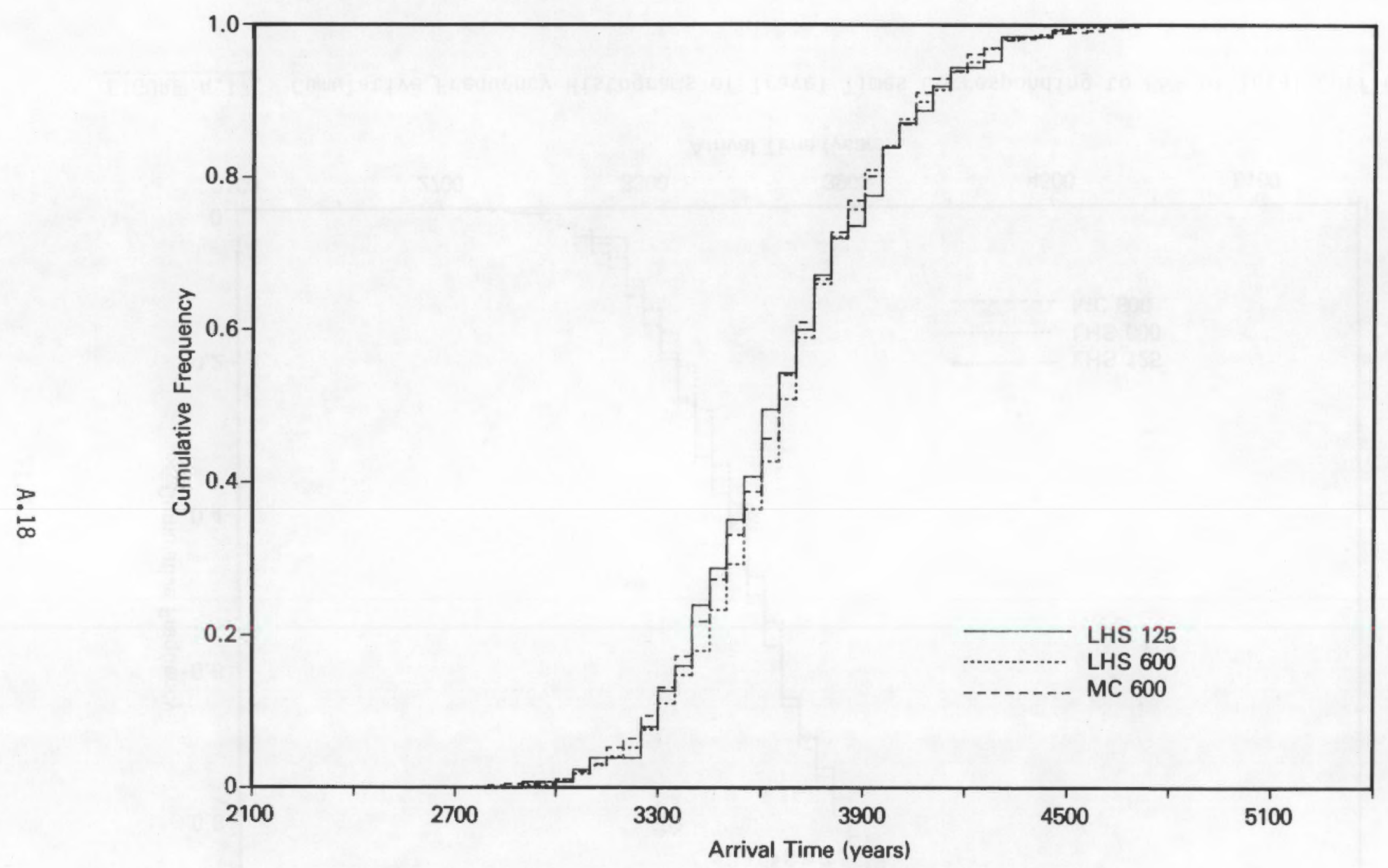

FIGURE A.18. Cumulative Frequency Histograms of Travel Times Corresponding to $90 \%$ of Total Outflow 


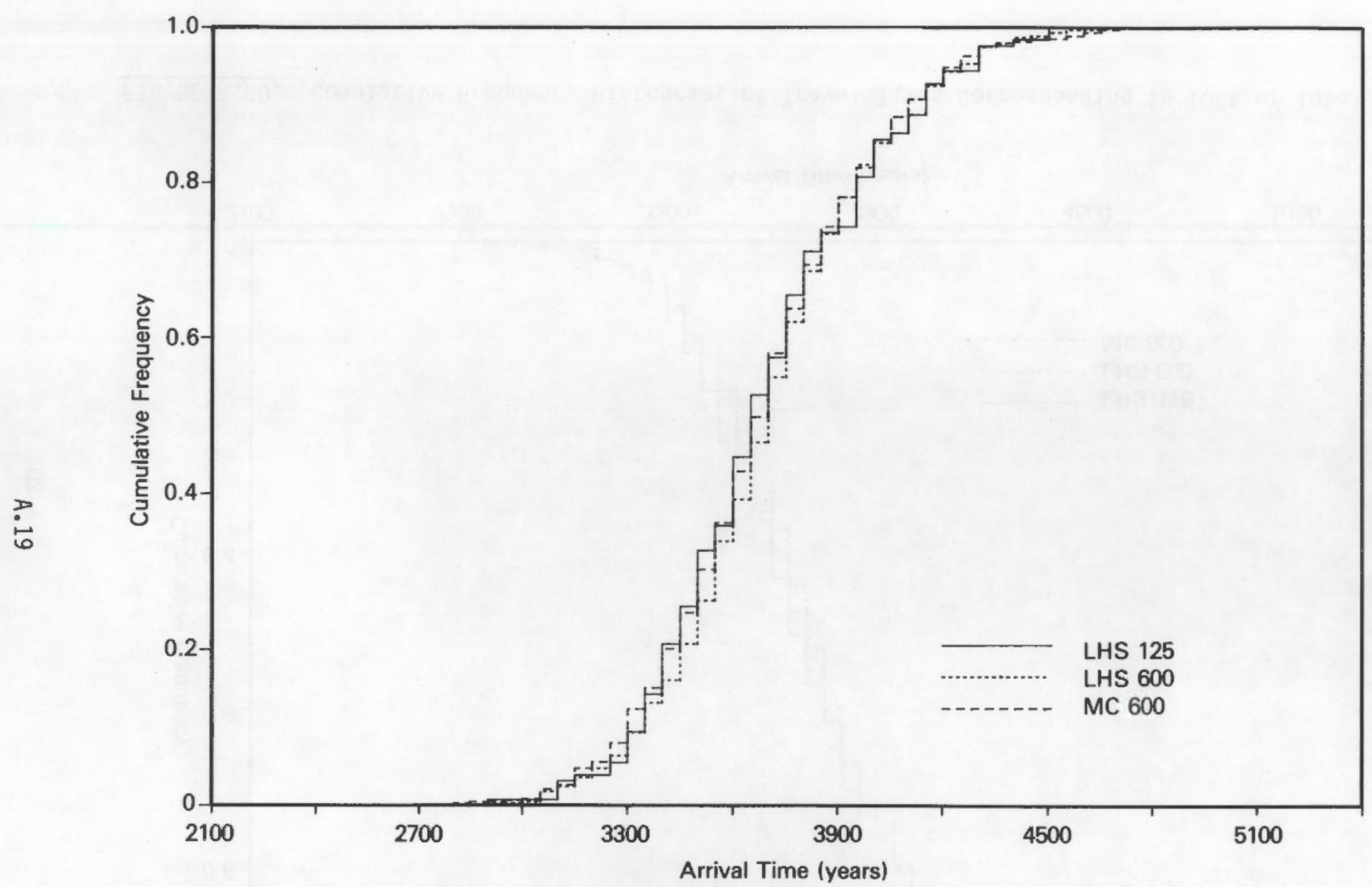

FIGURE A.19. Cumulative Frequency Histograms of Travel Times Corresponding to $95 \%$ of Total 0utflow 


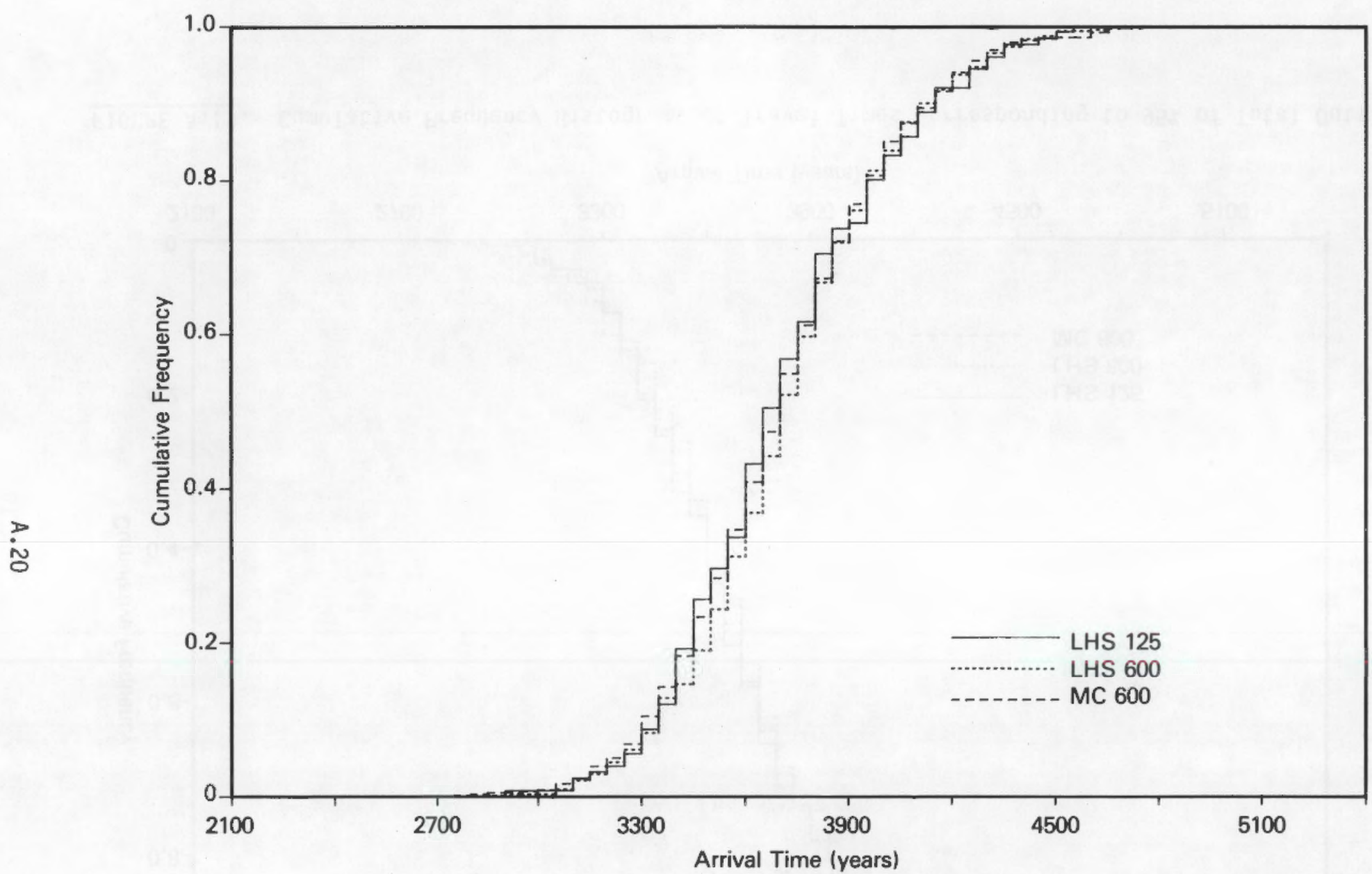

FIGURE A.20. Cumulative Frequency Histograms of Travel Times Corresponding to $100 \%$ of Total Outflow 


\section{DISTRIBUTION}

No. of

Copies

OFFSITE

U.S. Department of Energy

office of Civilian Radioactive Waste Management, RW-24

Washington, DC 20545

ATTN: N. A. Eisenberg (2)

D. H. Alexander

C. E. Kay, Acting Director

U.S. Department of Energy

Office of Civilian

Radioactive Waste

Management, RW-1

Washington, DC 20585

R. Stein

U.S. Department of Energy

Director of Engineering and Geotechnology, RW-23

Washington, DC 20585

10 DOE/Office of Scientific and

Technical Information

U.S. Department of Energy

Dffice of Civilian Radioactive Waste Management, RW-2D

Forrestal Building

Washington, OC 20585

ATTN:

T. H. Isaacs

S. H. Kale

U.S. Department of Energy

Office of Civilian Radioactive Waste Manaagement, RW-222

Forrestal Building

Washington, DC 20585

ATTN: J. F. Daly

M. W. Frei

J. L. Morris
No. of

Copies

B. G. Gale

U. S. Department of Energy

office of Civilian Radioactive

Waste Management, RW-223

Forrestal Building

Washington, DC 20585

C. L. Carnahan

Lawrence Berkeley Laboratory

MS 50E

1 Cyclotron Road

Berkeley, CA 94720

K. Chang

U.S. Nuclear Regulatory Cominission

Division of Waste Management

MS-623-SS

Silver Springs, MD 20910

W. J. Conover

College of Business

Administration

Texas Tech University

Lubbock, TX 79409

S. Coplan

U.S. Nuclear Regulatory Commission

MS-623-SS

Washington, DC 20555

G. A. Dinwiddie

U.S. Departinent of the Interior

U.S. Geological Survey

National Center, MS-41D

12202 Sunrise Valley Drive

Reston, VA 22092 
No. of

Copies

Document Control Center

U.S. Nuclear Regulatory Commission.

Division of Waste Management

Washington, DC 20555

W. Harrison

Argonne National Laboratory

6700 South Cass Avenue

Argonne, IL 60439

G. Jacobs

Oak Ridge National Laboratory

P.0. Box $X$

Bethel Valley Road

SM 038, Bidg. 1505

Oak Ridge, TN 37831

C. M. Jantzen

E.I. du Pont de Nemours \& Co., Inc.

Savannah River Laboratory

Aiken, SC 29808

J. K. Kerrisk

Los Alamos National Laboratory

Los Alamos, NM 87545

H. J. Machieis

Electric Power Research Institute

P.0. Box 10412

Palo Alto, CA 94303

D. L. 01 iver

University of Toledo

Mechanical Engineering

Department

Toledo, $\mathrm{OH} 43606$

C. Pescatore

Brookhaven National Laboratory

Upton, NY 11973
No. of

Copies

T. J. Nichol son

U.S. Office of Nuclear Regulatory Research Waste

Management Branch

5650 Nicholson Lane

Rockville, MD 20852

L. R. Rickertson

Weston

955 L'Enfant Plaza

Washington, DC 20024

B. Ross

Disposal Safety Inc. 1629 K Street NW, Suite 600

Washington, DC 20006

K. W. Stephens

Stephens \& Associates

10424 windfall Court

Damascus, MD 20872

Lawrence Livermore National Laboratory

P.0. Box 808

Livermore, CA 94550

ATTN: W. J. O'Connel

M. Revelli

H. Shaw

R. Silva

Office of Waste Technoiogy Development

7000 South Adams Street

Willowbrook, IL 60521

ATTN: H. Avci

A. Branstetter

University of California

Department of Nuclear

Engineering

Berkeley, CA 94720

ATTN: W. H.-L. Lee

T. H. Pigford 
No. of

Copies

U.S. Department of Energy Chicago Operations office 6800 South Cass Avenue

Argonne, IL 60439

ATTN: $H$. Ahagen

R. Baker

S. Mann

N. Patera

Sandia National Laboratory P.0. Box 5800

Albuquerque, NM 87185

ATTN: $F$. Bingham

M. Bl anchard

E. J. Bonano

R. W. Cranwell

T. O. Hunter

R. L. Iman

U.S. Department of Energy Nevada Operations office

P.0. Box 14100

Las Vegas, NV 89114-4100

ATTN: D. Livingston

C. Gertz

Battel le Memorial Institute P.0. Box 16594

Columbus, $\mathrm{OH}$ 43201-6594

ATTN: W. V. Harper

J. F. Kircher

I.T. Corporation

2340 Al amo SE

Albuquerque, NM 87106

ATTN: W. E. Coons

J. Myers

\section{FOREIGN}

G. Bidoglio

Joint Research Centre Radiochemistry Division

21020 Ispra (VA)

ITALY
No. of

Copies

N. C. Garisto

AECL - Whiteshell Nuciear Research Establishment

Pinawa, Manitoba

CANADA ROE $1 L O$

B. Grambow

Hahn-Meitner-Institut

GMBH, Postfach 390128

Glienicker Str. 100

D-1000 Berlin 39

FEDERAL REPUBLIC OF GERMANY

ง. Hadermann

Institut Federal de Recherches

en Matiere de Reacteurs

$\mathrm{CH}-5303$ wurenl ingen

SWITZERLAND

D. Hodgkinson

Theoretical Physics Division Atomic Energy Research Establ ishment

Harwell

OXON OX11 ORA

UNITED KINOGOM

L. H. Johnson

$A E C L$ - Whiteshell Nuclear Research Establishment

Pinawa, Manitoba

CANADA ROE 1LO

N. Kjellbert

$S K B A B$

P.0. Box 5864

S-102 48 Stockholm

SWEDEN

D. M. LeNeveu

AECL - Whiteshell Nuclear Research Establishement

Pinawa, Manitoba

CANDADA ROE ILO 
No. of

Copies

W. Lutze
Hahn-Meitner Institut
Department of Ceramic Materials
Posfach 390128
Glienicker Str. 100
D-1000 Beri in 39
FEDERAL REPUBLIC OF GERMANY
C. McCombie
NAGRA
Parkstrasse 23
CH-5401 Baden
SWITZERLAND
I. MCKinley
NAGRA
ParkStrasSe 23
CH-5401 Baden
SWITZERLAND

T. Mishima

Power Reactor and Nuclear Fuel Development Corporation Deputy General Manager Waste Isolation of fice Waste Management and Row

Materials Division 1-9-13 Akasaka, Minato-ku

Tokyo 107

JAPAN

I. Neretnieks

Royal Institute of Technology Department of Chemical

Engineering

S-100 44 Stockholm

SWEDEN

E. Peltonen

TVo Industrial Power Co. Ltd. Fredrikinkatu 51-53

Helsinki

FINLAND
No. of

Copies

\author{
S. Sharland \\ Atomic Energy Research \\ Establishment \\ Theoretical Physics Division \\ Harwel? \\ OxOn 0X11 ORA \\ UNITED KINGDOM \\ C. Thegerstrom \\ OECD/Nuclear Energy Agency \\ Division of Radiation \\ Protection and Waste \\ Management \\ 38 Boulevard Suchet \\ F-75016 Paris \\ FRANCE \\ H. Wanner \\ Nuclear Energy Agency \\ Oata Bank \\ Batiment 445 \\ 91191 Gif-sur-Yvette Cedex \\ FRANCE \\ L. 0. Werme \\ Swedish Nuclear Fuel and Waste \\ Management $\mathrm{Co}$. \\ P.0. Box 4864 \\ S-102 48 Stockholm \\ SWEDEN
}

ONSITE

4 DOE Richland Operations Office

M. S. Karol

A. J. Knepp

D. C. Langstaff

J. J. Sutey

Westinghouse Hanford Company

J. D. Davis 
No. of

Copies

60 Pacific Northwest Laboratory

M. J. Apted

W. W. Ballard

D. J. Bradley

J. A. Buchanan

R. L. Cheatham

C. R. Cole

P. G. Doctor (5)

C. E. Elderkin

P. W. Eslinger

J. W. Falco

M. G. Foley

M. D. Freshley

R. O. Gilbert

M. J. Graham

J. M. Hales

K. R. Hanson

P. C. Hays

E. A. Jacobson 17
No. of

Copies

C. T. Kincaid

A. M. Liebetrau

J. A. Mahaffey

R. W. Nelson

A. R. Olsen

M. G. Piepho

P. W. Reitmus

B. Sagar

R. L. Skaggs

G. M. Stokes

R. A. Stokes

J. A. Stottlemyre

A. E. Van Luik

G. Whelan

R. E. Wildung

Publjshing Coordination (2)

Technica\} Report Files (5) 


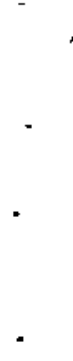

-

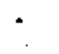

. 